\title{
Productivity Dynamics and the Role of "Big-Box" Entrants in Retailing
}

Florin Maican and Matilda Orth 


\title{
Productivity Dynamics and the Role of "Big-Box" Entrants in Retailing*
}

\author{
Florin Maican ${ }^{\dagger}$ and Matilda Orth ${ }^{\ddagger}$ \\ August 31, 2015
}

\begin{abstract}
The entry of large ("big-box") stores and the accompanying drastic decrease in the overall number of stores represent a striking trend in retail. We use a dynamic model to measure the impact of the entry of large stores on incumbents' productivity separate from demand while accounting for local markets and the endogeneity of entry. Using data on all retail food stores in Sweden, we find that incumbents' productivity increases after the entry of large stores and that the magnitude of the increase declines toward the upper part of the productivity distribution. Our findings highlight that large entrants play a crucial role in driving productivity.

Keywords: Retail markets; imperfect competition; industry dynamics; productivity; dynamic structural model.

JEL Classification: C24, L11, L50, L81, O3.

${ }^{*}$ We would like to thank the editor, two anonymous referees, Daniel Ackerberg, Victor Aguirregabiria, Mats Bergman, Jan De Loecker, Pierre Dubois, Martin Dufwenberg, Paul Grieco, Lennart Hjalmarsson, Randi Hjalmarsson, Jordi Jaumandreu, Amil Petrin, Vincent Réquillart, Mark Roberts, Rune Stenbacka, Johan Stennek, Måns Söderbom, and seminar participants at Toulouse School of Economics and the University of Gothenburg for valuable comments and discussions. In addition, we thank participants at EEA 2008 (Milan), EARIE 2007 (Valencia), the Nordic Workshop in Industrial Organization 2007 (Stockholm), the Conference of the Research Network on Innovation and Competition Policy 2007 (Mannheim), and the Swedish Workshop on Competition Research 2007 (Stockholm) for helpful comments and suggestions. Special thanks to the Trade Union Institute for Economic Research (FIEF) and the Swedish Retail Institute (HUI) for providing the data. We gratefully acknowledge financial support from the Swedish Competition Authority and the Jan Wallander and Tom Hedelius Foundation.

${ }^{\dagger}$ Research Institute of Industrial Economics (IFN) and University of Gothenburg, Box 640, SE-405 30, Göteborg, Sweden, Phone +46-31-786 4866, Fax +46-31-786 4154, E-mail: florin.maican@economics.gu.se

${ }^{\ddagger}$ Research Institute of Industrial Economics (IFN), Box 55665, SE-102 15, Stockholm, Sweden, Phone +46-8-665 4531, Fax +46-8-665 4599, E-mail: matilda.orth@ifn.se
\end{abstract}




\section{Introduction}

A major structural change in retail markets during the last few decades has been the entry of large ("big-box") stores and a drastic decrease in the overall number of stores. This trend has been accompanied by intensive investment in information technologies and innovations to cut costs. The most striking example is the expansion of Walmart in the U.S. ${ }^{1}$ Retail markets in Europe have also followed the "big-box" trend, although on a smaller scale. Some examples of big-box stores in European countries include Carrefour, Metro, Schwartz, and Tesco. Despite the significant structural shift toward big-box stores, the impact on productivity has received little attention.

This paper uses a dynamic structural model to estimate total factor productivity in retail markets and to quantify the effect of increased competition from the entry of large stores on incumbents' productivity and demand. Detailed data on all retail food stores in Sweden from 1996 to 2002 give us a unique opportunity to investigate the questions at hand.

Incumbent stores can respond strategically to big-box entry, and such responses are likely to be heterogeneous. For example, stores can lower their prices, increase their product offerings, or change their quality (Basker and Noel, 2009; Matsa, 2011; Basker et al., 2012). Stores can also respond by investing in new technology and improving their management practices, logistics, and inventory management to increase productivity.

Productivity in services and retail industries is not well understood. In fact, few studies go beyond measures such as sales and value-added per unit of input. ${ }^{2}$ We present a first attempt to use a structural framework for estimating total factor productivity in retail markets and provide a general strategy to identify the effect of large store entrants on productivity separate from demand. We address several aspects of productivity in retail markets. First, we account for the fact that stores can substitute labor

\footnotetext{
${ }^{1}$ Basker (2005), Basker (2007), Jia (2008), Haltiwanger et al. (2010), Ellickson and Grieco (2013), Ellickson (2015).

${ }^{2}$ Some recent studies that focus on labor productivity are, e.g., Foster et al. (2006), Haltiwanger et al. (2010), Schivardi and Viviano (2011), Basker (2012), and Ellickson and Grieco (2013).
} 
and capital investments. This consideration is important because retail stores have invested heavily in new technologies such as scanner and barcode techniques to increase self-service, which has substantially decreased the cost of labor (Basker, 2012). Second, we recognize that productivity in service industries suffers from problems related to measuring output. When sales or value-added is used as an output, productivity might increase because stores with market power in local markets can set higher prices (Foster et al., 2008). Third, we view large store entrants as part of the local market environment and thus recognize that they affect incumbents' productivity and exit.

The modeling framework takes into account that store productivity can be influenced by the external environment in which stores operate and by internal factors. Many questions remain open regarding external drivers of productivity (Syverson, 2011). The external environment can influence productivity in at least two ways. The first is through productivity gains within stores. Such gains can arise due to spillovers where stores have a one-time opportunity to learn best business practices related to, for example, management from a large store entrant in the local market. The second is through selection, whereby competition induces productivity improvements among surviving stores and forces low-productivity stores to exit. We quantify the overall effect of large store entrants on productivity rather than modeling all of the possible sources of productivity improvement. Our approach considers that increased competition reduces slack and improves productivity (X-inefficiency) (Leibenstein, 1966; Syverson, 2011).

Our dynamic structural model builds on recently developed methods of estimating production functions that have been almost exclusively applied to manufacturing industries (Olley and Pakes, 1996). ${ }^{3}$ The objective of these methods is to understand productivity heterogeneity within industries (Ericson and Pakes, 1995). The modeling of the external environment in local markets is in addition to the scarce literature on how to measure

\footnotetext{
${ }^{3}$ Levinsohn and Petrin (2003), Ackerberg et al. (2007), De Loecker (2011), Doraszelski and Jaumandreu (2013), Gandhi et al. (2014), and Ackerberg et al. (2015).
} 
and understand heterogeneity in productivity in retail markets. ${ }^{4} \mathrm{~A}$ central feature of the proposed model is that stores are allowed to react differently to large store entry, thus allowing us to calculate a productivity response by each store in the data. We evaluate the effects of large store entrants on different parts of the distribution of local market productivity, aggregate weighted productivity in local markets, and exit.

To disentangle the effect of large store entrants on productivity from demand, we augment the production function with a simple horizontal product differentiation demand system, whereby exogenous demand shifters and large store entrants affect prices (Klette and Griliches, 1996; De Loecker, 2011). ${ }^{5}$ Our joint model of productivity and demand addresses four endogeneity concerns. The first two relate to endogeneity of large store entry and output in local markets. These concerns are addressed using political preferences, previous periods' output, and characteristics of neighboring markets as instruments. The last two concerns relate to standard problems of simultaneity of input usage with productivity and selection on exit in estimation of the service-generating function (Ackerberg et al., 2007). Because retail markets are characterized by lumpy investments and difficulties in measuring product stocks, we recover productivity from the store labor demand function (Levinsohn and Petrin, 2003; Doraszelski and Jaumandreu, 2013).

Food retail is an important industry because groceries account for a substantial share (15 percent) of private consumption (Statistics Sweden, 2005). The structural shift toward larger but fewer stores is striking in Sweden. The total number of stores decreased by 17 percent, whereas the

\footnotetext{
${ }^{4}$ The paper also relates to the vast literature on how competition affects productivity. Previous theoretical work has emphasized both positive and negative effects, while empirical work has often emphasized positive effects. Examples of recent contributions are MacDonald (1994), Nickell (1996), Bertrand and Kramarz (2002), Djankov et al. (2002), Aghion and Griffith (2005), Greenstone et al. (2010), De Loecker (2011), Buccirossi et al. (2013), and Maican and Orth (2015).

${ }^{5} \mathrm{~A}$ quantity-based production function, which has begun to be used in manufacturing, is not suited for services because physical output is unobserved and thus lacks a unit of measure. Our study touches on the more general question of how to measure productivity in services, especially because of the rapid expansion of service markets such as information technology, e.g., Google (Syverson, 2011).
} 
share of large stores increased from 19 to 26 percent during our sample period 1996-2002. Average sales space increased by as much as 33 percent, but the total sales space remained virtually constant. Our framework is particularly attractive when applied to local markets that consist of many stores with independent pricing strategies and input decisions, as is the case in Sweden. Most stores operate as independent or franchise units affiliated with four major retail groups, of which only one operates as a cooperative. ${ }^{6}$

Our main results show that large store entrants force low-productivity stores to exit and surviving stores to increase productivity. The median incumbent increases productivity by 3.1 percent as a result of a large store entry. A key result is that productivity increases most among incumbents in the bottom part of the productivity distribution and declines with the productivity of incumbents. A large store entrant increases productivity by up to 1-2 percentage points more for a store in the 25th local market productivity percentile than for a store in the 75 th percentile. Stores with low productivity are small; i.e., they have fewer employees, lower capital stock, and less value-added. Productivity gains from large store entrants are higher if stores are affiliated with more retail groups in a local market. The median increase in store productivity is 2.3 and 3 percent in markets with two and four groups, respectively. We document the robustness of the results when alternative modeling specifications are used.

The possibility of documenting productivity gains arising from large store entrants has important policy implications. Entry regulations are in effect in the OECD, although such regulations are much more restrictive in Europe than in the U.S. ${ }^{7}$ Productivity is obviously an important object to study because it can be directly incorporated into a cost-benefit analysis of the entry of new large stores.

\footnotetext{
${ }^{6}$ While we recognize the importance of ownership in retail markets, we do not model ownership and only show descriptives from our single-agent model. There is a growing stream of literature that models entry while accounting for ownership in a dynamic oligopoly framework (Sweeting, 2010; Sweeting, 2013).

${ }^{7}$ The consequences of retail regulations (e.g., supermarket dominance) are frequently debated among policymakers in Europe (European Parliament, 2008; European Competition Network, 2011; European Commission, 2012). Maican and Orth (2015) find that more liberal entry regulations increase store productivity in the Swedish retail trade. See also Pilat (1997), Boylaud and Nicoletti (2001), and Griffith and Harmgart (2005).
} 
The next section describes the Swedish retail food market. Section 3 presents the model, whereas Section 4 presents the data. Section 5 discusses identification and estimation. Section 6 presents the empirical results and robustness checks, and Section 7 summarizes and draws conclusions. In several places, we refer to an online appendix containing various analyses that are not discussed in detail in the paper.

\section{The Swedish retail food market}

An important feature of the Swedish retail food market is that stores have independent pricing strategies. Indeed, must recognize that significant interactions between stores take place at the store level. Stores are affiliated with groups that historically collaborate on wholesale provision. ${ }^{8}$ Stores tend to operate as independent or franchise units that are relatively independent of their group affiliation. Decisions regarding inputs, pricing, and exit are thus traditionally made by individual store owners. Importantly, all groups have both small and large stores. In fact, the store size distributions are strikingly similar across group affiliations.

To reflect the fact that each store operates independently with its own pricing policy and to emphasize store level heterogeneity in productivity, we model each store as a separate unit. For our purposes, we focus on a recent increase in centralized decisions to enter large stores into local markets together with the historical network of independent and franchise stores. $^{9}$

Stores are affiliated with four major groups that each have a particular structure. ICA consists of a group of independent store owners that began through collaboration on wholesale provision. Axfood contains a mix of independent and franchise stores. Bergendahls has a mix of franchises and

\footnotetext{
${ }^{8}$ Previous research on Swedish food retailing uses the expressions group and wholesaler rather than firms (Asplund and Friberg, 2002; Chamber Trade Sweden, 2013).

${ }^{9}$ There has been a recent increase in centralized decisions related to the expansion of large stores. Although this centralization might also be reflected in exit decisions, such decisions are always made based on store performance.
} 
centrally owned stores and operates mainly in the south and southwest of Sweden. Coop, by contrast, consists of cooperatives, with decisions made at the local or national level. Despite its cooperative structure, independent store owners in Coop have the power to decide on, e.g., pricing and labor. The joint market share of stores affiliated with these four groups constituted approximately 92 percent of total sales in 2002. Stores affiliated with ICA constituted 44 percent of total sales. The corresponding figures were 22 percent for stores affiliated with Coop, 23 percent for stores affiliated with Axfood and 3 percent for stores affiliated with Bergendahls. Various independent owners made up the remaining 8 percent of the market share (fifth group). ${ }^{10}$

Large stores. The big-box expansion in Sweden comprises the entry of large hypermarkets. These large stores differ from other stores in a number of respects. For example, they operate almost exclusively in external locations, and a separate and sufficiently large parking lot is provided to customers. In contrast, stores located closer to consumers' homes and work are often easier to reach by foot, bike, or public transport. Large stores deliver broad product assortments with a high degree of self-service. There has been a rapid expansion of self-scanning, which is widespread in large stores. In addition, large stores often offer different services than other stores, including independent cafés and bakeries, gaming services and full pharmacies.

Entry regulation. The Plan and Building Act (PBA) empowers the 290 municipalities in Sweden to make decisions regarding the applications of new entrants. The main rationale for entry regulations is that new entrants generate both positive and negative externalities that require careful evaluation by local authorities. Advantages, such as productivity gains, lower prices, and wider product assortment, contrast with disadvantages,

\footnotetext{
${ }^{10}$ International groups with hard discount formats entered the Swedish market after the study period: Netto in 2002 and Lidl in 2003. Stores affiliated with ICA operated in almost all of the 290 markets. Coop decreased from 236 to 227 markets and Axfood from 276 to 266 during the study period. Bergendahls stores were in 21 markets at the beginning and 42 markets at the end. The median (mean) store sizes are 316 (540) square meters for stores affiliated with ICA, 350 (620) for Axfood, 400 (620) for Coop, and $448(1,297)$ for Bergendahls. Hence, most stores are small.
} 
notably, fewer stores and environmental effects. The PBA is viewed as a major barrier to entry, resulting in diverse outcomes, e.g., price levels, across municipalities (Swedish Competition Authority, 2001:4). Several reports emphasize the need to better analyze how regulation affects market outcomes (Swedish Competition Authority, 2001:4, 2004:2). Because large store entrants are expected to impact the market structure extensively, they are carefully evaluated by local governments. The online appendix (Section A) describes the PBA in greater detail.

Local markets. Food products fulfill daily needs and are often of relatively short durability. Thus, stores are located close to consumers. Travel distance when buying food is relatively short unless the prices are sufficiently low. Proximity to home and work are thus key considerations for consumers in choosing where to shop, although distance likely increases with store size. The size of the local market for each store depends on its type. Large stores attract consumers from a wider area than do small stores, but the size of the local market also depends on the distance between stores. We assume that retail markets are isolated geographic units, with stores in one market competitively interacting only with other stores in the same local market. A complete definition of local markets requires information about the exact distance between stores. Without this information, we must rely on existing measures.

The 21 counties in Sweden are clearly too large to be considered local markets for our purposes, and the 1,534 postal areas are probably too small, especially for large stores (on which we focus). The 88 local labor markets take into account commuting patterns, which are important for hypermarkets and department stores, while the 290 municipalities appear to be more suitable for large supermarkets.

An accurate definition of local markets reflects the fact that consumers think of all stores in the local market as their choice set. We believe municipalities are reasonable local markets in our setting for at least three reasons. The first is that survey evidence of shopping behavior shows that most consumers buy groceries in their municipality. According to surveys, more than 80 percent of Swedish consumers never or rarely buy groceries 
outside of their home municipality. More precisely, 17 percent never buy groceries outside of their municipality, 46 percent do so less than 1-2 times per month, and 23 percent do so 1-2 times per month (Swedish Trade Federation, 2011). ${ }^{11}$ The second reason is that municipal governments evaluate new entrants and thus have to account for the responses of all incumbents in the municipality. The third reason is that distance measures show that the average distance for consumers to the nearest store in the municipality is 2.3 kilometers. The corresponding average distance to the second nearest store is 4 kilometers. In virtually all municipalities, the nearest store for over 80 percent of the population is within 15 kilometers.

Given the information from surveys, regulations, and descriptive distance measures, we believe that it is reasonable to use municipalities as local markets. We exclude the three largest metropolitan municipalities (Stockholm, Göteborg, Malmö), which are likely to consist of submarkets. The population in the remaining markets ranges from 3,244 to 192,496. The average market consists of 25,836 people, whereas the median market consists of 15,133 people.

\section{Modeling the impact of large store en- trants on productivity}

This paper uses a general strategy to measure the effect of entry of large stores on incumbents' productivity shocks while controlling for local market characteristics and unobserved prices.

Service-generating function. Stores sell products and services according to Cobb-Douglas technology:

$$
Q_{j t}=L_{j t}^{\beta_{l}} K_{j t}^{\beta_{k}} \exp \left(\omega_{j t}+u_{j t}^{p}\right),
$$

\footnotetext{
${ }^{11}$ Only 15 percent buy their groceries outside of the municipality more than 1-2 times a month. Moreover, 71 percent of consumers travel by car to buy groceries.
} 
where $Q_{j t}$ is the service output by store $j$ at time $t ; L_{j t}$ is the labor input; $K_{j t}$ is capital stock; $\omega_{j t}$ is store productivity; ${ }^{12}$ and $u_{j t}^{p}$ are the service output shocks. ${ }^{13}$ The service output $Q_{j t}$ does not include items that are purchased from the wholesaler and sold in the store, i.e., intermediate inputs.

Stores know their productivity $\omega_{j t}$ when they make their input and exit decisions. Store productivity is correlated over time, and it is unobserved by the researcher. We assume that store productivity follows a controlled first-order Markov process, i.e., $P\left(\omega_{j t} \mid \omega_{j t-1}, e_{m t-1}^{L}\right)$, where $e_{m t-1}^{L}$ is the number of large store entrants in market $m$ in year $t-1$. Accounting for the external environment in the productivity process allows for heterogeneous store responses to large store entry. The model allows for a flexible relationship between store productivity and large store entrants, which is discussed in detail below. ${ }^{14}$ The previous number of large store entrants affects not only the $\omega_{j t}$ but also after the period $t$ through $\omega_{j t}$, i.e., the effect of large store entrants in each period accumulates into productivity. ${ }^{15}$

The external environment in which stores operate can influence productivity in at least two ways. The first is through productivity gains within stores. Such productivity gains can arise due to spillovers, where stores have a one-time opportunity to learn best business practices from a large store entrant in the local market. The second is through the fact that more intense competition induces selection among stores with different levels of productivity, which increases average productivity and forces low-productivity stores to exit (Syverson, 2011).

We measure the overall effect of large store entrants on store produc-

\footnotetext{
${ }^{12}$ Other technology functions, such as translog, can be used (see robustness section).

${ }^{13}$ In the case of value-added, $u_{j t}^{p}$ may be associated with measurement error when there is the same measurement error in intermediate inputs and output (Gandhi et al., 2014).

${ }^{14}$ We follow the common notation of capital letters for levels and small letters for logs for all variables except for the number of large store entrants $e^{L}$, which is in levels.

${ }^{15}$ The way that we model the relationship between store productivity and large store entrants is complementary to previous work on retail productivity (e.g., Foster et al., 2006, Schivardi and Viviano, 2011, Basker et al., 2012, Ellickson and Grieco, 2013). For example, Ellickson and Grieco (2013) use detailed spatial and panel data to quantify changes in growth rates every year before and after entry. None of these papers focus on a structural approach of modeling total factor productivity and large store entry.
} 
tivity as it relates to X-inefficiency. An additional large store entrant in the market decreases the service output (competition effect). To compensate for the decrease in service output, stores try to reduce their slack to continue to operate. The fact that it takes time for stores to adjust their productivity in response to increased competition justifies a lagged effect of large store entrants on productivity.

Because service output is difficult to measure in retail markets and is therefore unobserved in many data sets, deflated value-added is often used as a proxy for service output. In this case, store prices are included in the output measure, and they affect the productivity measure. In other words, the productivity measure includes price and demand variations (Foster et al., 2008). Thus, the relationship between measured productivity and large store entrants is affected by the impact of large store entrants on prices and demand. To isolate the effect of large store entrants on productivity, we consider a standard horizontal product differentiation demand system (CES):

$$
Q_{j t}=Q_{m t}\left(\frac{P_{j t}}{P_{m t}}\right)^{\eta} \exp \left(\mu_{j t}\right),
$$

where $Q_{m t}$ is the aggregated service output in local market $m$; $P_{j t}$ is the service output price of store $j ; P_{m t}$ is the average price in the market; and $\mu_{j t}$ represents store level shocks to demand (Klette and Griliches, 1996; De Loecker, 2011). The parameter $\eta(<-1$ and finite) captures the elasticity of substitution among stores. ${ }^{16}$ The demand system implies a single elasticity of substitution for all stores. Thus, there are no differences in cross-price elasticities, i.e., we have a constant markup over marginal cost $\left(\frac{\eta}{1+\eta}\right)$, and the Lerner index is $\left(\frac{1}{|\eta|}\right)$. This simple demand system is suitable for retail markets where stores have independent pricing strategies and the local markets consist of many stores, such that a single store does not influence the market price.

Combining the service output (1) and demand equation (2), we obtain an expression for the log of deflated value-added $\left(y_{j t}\right)$ as a function of inputs

\footnotetext{
${ }^{16}$ The vertical dimension is to some extent also captured because deflated output measures both quantity and quality, which is correlated with store type (size).
} 
and local market output:

$$
\begin{aligned}
y_{j t} \equiv & q_{j t}+p_{j t}-p_{m t}=\left(1+\frac{1}{\eta}\right)\left[\beta_{l} l_{j t}+\beta_{k} k_{j t}\right]-\frac{1}{\eta} q_{m t}+\left(1+\frac{1}{\eta}\right) \omega_{j t} \\
& -\frac{1}{\eta} \mu_{j t}+\left(1+\frac{1}{\eta}\right) u_{j t}^{p}
\end{aligned}
$$

where $p_{j t}$ and $p_{m t}$ are logs of the service output prices at the store and market levels, respectively.

Estimation of the service-generating function (3) involves controls for both unobserved productivity $\omega_{j t}$ and unobserved demand shocks $\mu_{j t}$. In the retail industry, other local market characteristics can explain store price variation in addition to the log of store output $q_{j t}$ and the log of market output $q_{m t}$. For example, differences in the number of large store entrants across local markets over time likely affect unobserved demand shocks $\mu_{j t}$ and, therefore, store prices. We decompose demand shocks $\mu_{j t}$ into observed local market characteristics $\mathbf{x}_{m t}$ and the number of large stores that enter a local market in period $t, e_{m t}^{L}$ :

$$
\mu_{j t}=\beta_{e} e_{m t}^{L}+\mathbf{x}_{m t}^{\prime} \boldsymbol{\beta}_{x}+u_{j t}^{d}
$$

where $u_{j t}^{d}$ are remaining unobserved demand shocks. Controlling for demand shocks $\mu_{j t}$ in the service-generating function (3) yields the specification taken to the estimation

$$
\begin{aligned}
y_{j t}= & \left(1+\frac{1}{\eta}\right)\left[\beta_{l} l_{j t}+\beta_{k} k_{j t}\right]-\frac{1}{\eta} q_{m t}-\frac{1}{\eta} \beta_{e} e_{m t}^{L}-\frac{1}{\eta} \mathbf{x}_{m t}^{\prime} \boldsymbol{\beta}_{x} \\
& +\left(1+\frac{1}{\eta}\right) \omega_{j t}-\frac{1}{\eta} u_{j t}^{d}+\left(1+\frac{1}{\eta}\right) u_{j t}^{p} .
\end{aligned}
$$

The remaining shocks in (5) are grouped into $\epsilon_{j t}$, where $\epsilon_{j t}=-\frac{1}{\eta} u_{j t}^{d}+(1+$ $\left.\frac{1}{\eta}\right) u_{j t}^{p}$.

How to recover productivity and assess the relationship between store productivity and the number of large store entrants in a market is complex, especially because it relates to how competition from large store entrants affects productivity. In our setting, stores compete in the product market and collect their payoffs. At the beginning of each time period incumbents decide whether to exit or continue to operate in the local market. The 
shocks $u_{j t}^{p}$ and $u_{j t}^{d}$ are not predictable during the period in which inputs can be adjusted and stores make exit decisions. Stores are assumed to know their scrap value received upon exit $\gamma$ prior to making exit and investment decisions. If the store continues, it chooses optimal levels of investment $i$ and labor $l$. Store $j$ maximizes the discounted expected value of future net cash flows using the Bellman equation (Olley and Pakes, 1996):

$$
V\left(\mathbf{s}_{j t}\right)=\max \left\{\gamma \underset{i_{j t}}{\gamma} \sup _{i_{j t}}\left[\pi\left(\mathbf{s}_{j t}\right)-c_{i}\left(i_{j t}, k_{j t}\right)+\beta E\left[V\left(\mathbf{s}_{j t+1}\right) \mid \mathcal{F}_{j t}\right]\right\},\right.
$$

where $\mathbf{s}_{j t}=\left(\omega_{j t}, k_{j t}, w_{j t}, q_{m t}, p_{m t}, e_{m t}^{L}, \mathbf{x}_{m t}\right) ; w_{j t}$ is the log of the wage rate at the store level; $\beta$ is a store's discount factor; $\pi\left(\mathbf{s}_{j t}\right)$ is the profit function, which is increasing in both $\omega_{j t}$ and $k_{j t} ; c_{i}\left(i_{j t}, k_{j t}\right)$ is the investment cost of new capital (equipment), which is increasing in investment choice $i_{j t}$ and decreasing in current capital stock $k_{j t}$ for each fixed $i_{j t}$ (Pakes, 1991); and $\mathcal{F}_{j t}$ represents the information available at time $t$. We assume that capital is a dynamic input that accumulates according to $K_{t+1}=(1-\delta) K_{t}+\exp \left(i_{t}\right)$, where $\delta$ is the depreciation rate. In our setting, groups decide about the entry of large stores, and individual stores cannot influence this decision. Local market shifters and wages follow exogenous processes.

The solution to a store's dynamic maximization problem (6) yields optimal policy functions for investment $i_{j t}=\tilde{i}_{j t}\left(\mathbf{s}_{j t}\right)$ and exit $\chi_{j t+1}=\tilde{\chi}_{j t}\left(\mathbf{s}_{j t}\right)$. The exit rule $\chi_{j t}$ depends on the threshold productivity $\underline{\omega}_{m t}$, which is a function of all state variables except store productivity (Olley and Pakes, 1996). A store continues $\left(\chi_{j t}=1\right)$ if its productivity is larger than the local market threshold $\left(\omega_{j t}>\underline{\omega}_{m t}\right)$. We assume that labor $l_{j t}=\tilde{l}_{j t}\left(\mathbf{s}_{j t}\right)$, which is part of profits $\pi(\cdot)$, is chosen to maximize short-run profits (Levinsohn and Petrin, 2003; Doraszelski and Jaumandreu, 2013). ${ }^{17}$

Productivity for stores that continue to operate in period $t$ follows a Markov process

$$
\omega_{j t}=h\left(\omega_{j t-1}, e_{m t-1}^{L}, \mathscr{P}_{j t}\right)+\xi_{j t},
$$

\footnotetext{
${ }^{17}$ If labor has dynamic implications (e.g., in the case of labor adjustment costs), then labor in the previous period is part of the state space, and the optimal policy function for labor $l_{j t}=\tilde{l}_{j t}\left(\mathbf{s}_{j t}\right)$ is derived from solving the dynamic optimization problem (6).
} 
where $h(\cdot)$ is an approximation of the conditional expectation, and $\xi_{j t}$ are shocks to productivity that are mean-independent of all information known at $t-1 .^{18} \mathscr{P}_{j t}$ are predicted survival probabilities of being in the data in period $t$, conditional on the information in $t-1, \mathscr{P}_{j t}=\operatorname{Pr}\left(\chi_{j t}=1 \mid \mathcal{F}_{t-1}\right)$ (Olley and Pakes, 1996). Two stores with the same productivity and capital have different distributions of future productivities if they operate in local markets with a different number of large store entrants.

A timing assumption distinguishes an incumbent's response to large store entrants on demand from productivity. Large store entrants immediately affect stores' residual demand and thus local market equilibrium prices but affect store productivity with a one-year lag. The plausibility of this timing assumption for service industries ultimately depends on the empirical application at hand. More generally, several aspects could validate this assumption for retailing. First, intensive investments in information technology, such as scanners, have enabled stores to quickly adjust prices at a low cost (Basker, 2015). Consumers can also easily switch stores. Second, it is likely that it takes time for stores to adopt new technologies and take advantage of improvements in, for instance, management and logistics. ${ }^{19}$ De Loecker (2011) uses a similar timing assumption when analyzing productivity effects from trade liberalization in the textile industry. Indeed, this timing assumption is particularly appealing in local retail markets that consist of many stores and where stores apply independent pricing strategies. Subsection 5.1 discusses additional remarks on the timing assumption of the entry of large stores.

\footnotetext{
${ }^{18}$ With focus on the existence of large stores and thus on the stock of large store entrants, the productivity process can be modeled as $\omega_{j t}=\gamma_{e} e_{m t-1}^{L}+\xi_{j t}$, where $\xi_{j t}$ follows an $A R(1)$ process, i.e., $\xi_{j t}=\rho \xi_{j t-1}+b_{j t}$, where $b_{j t}$ are i.i.d. shocks. First, this approach implies that the productivity effect is on the rate of change; i.e., productivity increases for all future periods after the entry of a large store. Second, the productivity process can be rewritten as $\omega_{j t}=\rho \omega_{j t-1}+\gamma_{e} e_{m t-1}^{L}-\rho \gamma_{e} e_{m t-2}^{L}+b_{j t}$. This modeling specification implies that the data should be lagged twice, which is a significant drawback for short panels.

${ }^{19}$ This assumption directly follows the assumptions in recent work on dynamic structural models of R\&D and productivity, where investment in R\&D affects productivity with a one-year lag (e.g., Ericson and Pakes, 1995; Doraszelski and Jaumandreu, 2013). A major difference is that we consider the role of the external environment (large store entry) rather than at firm's choices of R\&D.
} 
We base our empirical strategy on stores' static decisions on labor to disentangle the relationship between current productivity, entry of large stores, and future productivity (Doraszelski and Jaumandreu, 2013). Three major concerns are addressed when estimating the service-generating function (5). The first concern relates to the standard problems of simultaneity of input usage on productivity, i.e., labor and capital are correlated with store productivity. All endogeneity problems regarding inputs are concentrated in $\omega_{j t}$. The labor demand function $l_{j t}=\tilde{l}_{j t}\left(\mathbf{s}_{j t}\right)$ allows us to recover the unobserved productivity $\omega_{j t}$, to control for it in the service-generating function (5) and to use it in the productivity process (7). The second concern addresses selection on exit due to productivity. The third concern addresses the endogeneity of local market quantity $q_{m t}$ and entry of large stores $e_{m t}^{L}$ due to their possible correlation with remaining demand shocks $u_{j t}^{d}$ in $\epsilon_{j t}$. The next section presents the data that support our identification strategy. Section 5 discusses the identification and estimation.

\section{Data}

The estimation of our service-generating function requires store-level data on output, inputs, wages, entry and exit. It also requires municipality-level data on aggregate output and local market characteristics. We use two micro data sets that both contain yearly information on all retail food stores in Sweden from 1996 to 2002.

The first data set is provided by Delfi Marknadspartner (DELFI) and contains information about store type, chain/firm, and square meters of sales space. A unit of observation is a store based on its geographic location (i.e., only its address). A store is assumed to enter if it is observed in the data in year $t$ but not $t-1$, and a store is assumed to exit if it is observed in year $t$ but not $t+1$. DELFI is used to define large store entrants based on physical entry and detailed store type definitions.

The second data set is provided by Statistics Sweden (SCB) and contains sales, value-added, investments, capital, the number of full-time ad- 
justed employees, and full-time adjusted wages for all organization numbers. The data are based on tax reporting and contain all organization numbers belonging to SNI code 52.1, "Retail sales in non-specialized stores". ${ }^{20}$ Organization number is the most disaggregated level for which accurate input and output measures exist. ${ }^{21}$ In a few cases, an organization number can consist of more than one store (a "multi-store") in the same municipality for which we observe total, not average, inputs and outputs. ${ }^{22}$ The SCB also provides municipality demographics such as population, population density, and average income. In addition, it contains political preferences in municipalities throughout the election periods 1994-1998 and 1999-2002. The SCB data are used to estimate productivity for each organization number and year. ${ }^{23}$ Online appendix A provides more information about the data.

Large store entrants. We define the five largest types of stores (hypermarkets, department stores, large supermarkets, large grocery stores, and other ${ }^{24}$ ) as "large" and four other types of stores (small supermarkets, small grocery stores, convenience stores, and mini markets) as "small." This classification accords with the Swedish Competition Authority (see, e.g., Swedish Competition Authority, 2002:6). In terms of the Swedish market, we believe that these types are representative of being "large." ${ }^{25}$ In light

\footnotetext{
${ }^{20}$ Swedish National Industry (SNI) classification codes build on the EU standard NACE

${ }^{21} \mathrm{~A}$ so-called organization number specifies the identity of a corporate body. The Swedish Tax Authority (Skatteverket) has a register of all organization numbers used for tax reporting. The numbers are permanent and unique, i.e., one number follows the corporate body throughout its whole existence, and two identical organization numbers do not exist. The register contains the date of registration of the organization number and information regarding any exit/bankruptcy (Swedish Tax Authority, 2011). Anonymous codes in FS-RAMS indicate that we do not know the exact identity of an organization number.

${ }^{22}$ In the SCB data, we observe the municipality in which each organization number is physically located. Further, entry and exit are defined only on the basis of organization numbers. Exit in the SCB may thus be due to a re-organization, for example.

${ }^{23}$ We remove large store entrants from the SCB when estimating productivity.

${ }^{24}$ Stores classified as other stores are large and externally located.

${ }^{25}$ Because the store type classification in DELFI is extremely detailed, grouping stores into two size classes is not highly restrictive. Sales, sales space, and other store characteristics suggest that it is reasonable to group, e.g., hypermarkets and large grocery stores together and to separate large and small supermarkets (online appendix A). Alter-
} 
of the entry regulation, we only consider the physical entry of large stores (defined only based on address). A store that is re-classified into one of the large store types during the period is thus not counted as a large store entry. Gas station stores, seasonal stores, and stores under construction are excluded, as they do not belong to the SNI-code 52.1 in the SCB.

Descriptive statistics. Table 1 presents descriptive statistics of the Swedish retail food industry from the two data sets, DELFI and the SCB, for the period 1996-2002. In the SCB, the number of observations decreases by approximately 17 percent (from 3,714 to 3,067). The share of large stores increases from 19 percent to nearly 26 percent during the sample period. While total sales space remains virtually constant, mean sales space increases by 33 percent. This result suggests that there has been a major structural change toward larger but fewer stores. The wage-bill increases by over 22 percent (in real terms), while the number of employees increases by only 9 percent. Total sales increase by approximately 26 percent. Aggregate value-added per employee increases from SEK 247.22 thousand to SEK 277.69 thousand during the period (12 percent). The corresponding increase in value-added per sales space is from SEK 7.29 thousand to SEK 8.72 thousand (19 percent).

Table 2 shows the distribution of stores and groups across all local markets and years. The average number of stores is 23 , with a standard deviation of 35. A majority of markets consist of stores that belong to three groups, whereas almost no markets consist of stores that belong to a single group. In the upper part of the distribution, most stores belong to ICA, about twice as many as belong to Coop and Axfood. On average, as many as 7.25 stores belong to ICA, and slightly less than 4 each belong to Coop and Axfood.

Table 3 shows the median characteristics of local markets with and without large store entrants during the period 1997-2002. Based on all stores, average value-added per employee increases from SEK 249.33 thousand to SEK 266.28 thousand (7 percent) during the study period, whereas aver-

natively, we define observations in the SCB with sales above the 5th percentile of large store sales in DELFI as large and otherwise as small. The empirical results (available from the authors upon request) are consistent with those reported here. 
age value-added per sales space $\left(\mathrm{m}^{2}\right)$ increases from SEK 4.85 thousand to SEK 5.55 thousand (14 percent). The median number of stores varies from 22 to 54 in markets with large store entry, compared with 13 to 15 in non-entry markets. The number of markets with at least one large store entrant varies from 6 to 23. Among these, up to three large store entrants become established in the same market in the same year. As expected, median entry and exit are higher in large store entry markets than in nonentry markets, as are median population and population density.

\section{Identification and estimation}

This section discusses the identification and estimation of the servicegenerating function (5) based on the Olley and Pakes (1996) (OP) approach, which uses information about store input choices and exit decisions.

Recovering productivity. We use the labor demand function from the stores' static profit maximization problem to recover productivity together with a good measure of store-specific wages (Doraszelski and Jaumandreu, 2013). ${ }^{26}$ Using labor demand to recover productivity has the advantage that we can include stores with zero investment. The number of full-time adjusted employees is our measure of labor. Labor is a static and variable input chosen based on current productivity. For several reasons, this assumption is less restrictive in retail than in many other industries. First, part-time workers are common. As many as 40 percent of employees in food retail work part-time, compared with 20 percent in the Swedish economy as a whole (Statistics Sweden). In addition, the share of skilled labor is

\footnotetext{
${ }^{26}$ Intermediate inputs would be an excellent choice of proxy for productivity in retail markets (Levinsohn and Petrin, 2003). Ideally, we would like to have data on the stock of products (materials), but such data are unfortunately not available in many data sets on service industries. The complexity of food products and the fact that stores have different product assortments make it difficult to collect data on the stock of products for all stores. The investment policy function is restrictive because retail stores make lumpy investments, and we can only use stores with positive investment (Olley and Pakes, 1996).
} 
low in retail. Only 15 percent of all retail employees had a university education in 2002, compared with 32 percent in the total Swedish labor force (Statistics Sweden). Moreover, we find no systematic differences in hiring educated workers between small and large stores in our data. Stores have long and similar opening hours and adjust their labor due to variations in customer flows over the day, week, month, and year. The training process might also be shorter than in many other industries. ${ }^{27}$ We relax the static labor assumption in the robustness section.

The general labor demand function that arises from the stores' optimization problem (6) is $l_{j t}=\tilde{l}_{t}\left(\omega_{j t}, k_{j t}, w_{j t}, q_{m t}, p_{m t}, e_{m t}^{L}, \mathbf{x}_{m t}\right)$, where $\tilde{l}_{t}(\cdot)$ is an unknown function. To back out productivity, the following key assumptions must hold. First, the labor demand function must be strictly monotonic in productivity, which holds when labor is a static input and more productive stores do not have disproportionately higher markups than less productive stores. The labor demand function obtained from Cobb-Douglas technology is strictly increasing in productivity. In our case, the parametric labor demand function under imperfect competition derived from a store's static optimization problem is $l_{j t}=$ $\frac{1}{\left[\left(1-\beta_{l}\right)-\frac{1}{\eta} \beta_{l}\right]}\left[-\delta_{1}+\left(1+\frac{1}{\eta}\right) \omega_{j t}-w_{j t}+p_{m t}+\left(1+\frac{1}{\eta}\right) \beta_{k} k_{j t}-\frac{1}{\eta} q_{m t}-\frac{1}{\eta} \beta_{e} e_{m t}^{L}-\frac{1}{\eta} \mathbf{x}_{m t}^{\prime} \boldsymbol{\beta}_{x}\right]$, where $\delta_{1}=-\ln \left(\beta_{l}\right)-\ln \left(1+\frac{1}{\eta}\right)-\ln E\left[\epsilon_{j t}\right]$ (Doraszelski and Jaumandreu, 2013). ${ }^{28}$ By adding mild regularity conditions on a general technology in equation (1) instead of Cobb-Douglas technology, we can show that static labor demand is strictly increasing in productivity under imperfect competition (online appendix D provides the proof). One important condition is that labor's marginal product is increasing in productivity, which is fully consistent with store profit-maximization behavior. Second, $\omega_{j t}$ is the only unobservable entering the labor demand function, which rules out, e.g., measurement error, optimization error in labor, and a model in which exogenous productivity is not single dimensional. Our detailed register data

\footnotetext{
${ }^{27}$ We assume that the labor market is efficient, so there are no training, hiring or firing costs, no labor supply constraints for stores (they can hire when they want), and no labor market rigidities.

${ }^{28}$ Then, one can derive the parametric form for the inverse labor demand function, i.e., $\omega_{j t}=\frac{\eta}{1+\eta}\left[\delta_{1}+\left[\left(1-\beta_{l}\right)-\frac{1}{\eta} \beta_{l}\right] l_{j t}+w_{j t}-p_{m t}-\left(1+\frac{1}{\eta}\right) \beta_{k} k_{j t}+\frac{1}{\eta} q_{m t}+\frac{1}{\eta} \beta_{e} e_{m t}^{L}+\frac{1}{\eta} \mathbf{x}_{m t}^{\prime} \boldsymbol{\beta}_{x}\right]$.
} 
of wages for all employees in Swedish retail are less subject to measurement errors due to reporting. Third, we require helpful variation in store-specific wages. Even if store wages change over time, we need additional variation at the store level if we are to control for time effects in the estimation. ${ }^{29}$ The variation in store wages in our data is discussed in detail in the empirical implementation Section 5.2.

Estimation of the service-generating function is performed in two steps (OP framework). In the first step, we recover productivity from the inverse labor demand function. In the second step, we use the recovered productivity and productivity process to estimate the parameters of the servicegenerating function using the generalized method of moments (GMM) estimator.

Inverting the labor demand function $\tilde{l}_{t}(\cdot)$ to obtain productivity $\omega_{j t}$ and substituting it into (5), the service-generating function becomes

$$
y_{j t}=\phi_{t}\left(l_{j t}, w_{j t}, k_{j t}, q_{m t}, e_{m t}^{L}, \mathbf{x}_{m t}\right)+\epsilon_{j t},
$$

where $\phi_{t}(\cdot)=\left(1+\frac{1}{\eta}\right)\left[\beta_{l} l_{j t}+\beta_{k} k_{j t}\right]-\frac{1}{\eta} q_{m t}-\frac{1}{\eta} \beta_{e} e_{m t}^{L}-\frac{1}{\eta} \mathbf{x}_{m t}^{\prime} \boldsymbol{\beta}_{x}+\left(1+\frac{1}{\eta}\right) \omega_{j t}$. Estimation of (8) yields an estimate of $\phi_{t}(\cdot), \hat{\phi}_{t}$ and helps to recover productivity $\omega_{j t}$ without demand and service output shocks $\left(\epsilon_{j t}\right)$ :

$$
\begin{aligned}
\omega_{j t}(\boldsymbol{\beta})= & \frac{\eta}{(1+\eta)}\left[\hat{\phi}_{t}-\left(1+\frac{1}{\eta}\right)\left[\beta_{l} l_{j t}+\beta_{k} k_{j t}\right]+\frac{1}{\eta} q_{m t}+\frac{1}{\eta} \beta_{e} e_{m t}^{L}\right. \\
& \left.+\frac{1}{\eta} \mathbf{x}_{m t}^{\prime} \boldsymbol{\beta}_{x}\right]
\end{aligned}
$$

where $\boldsymbol{\beta}=\left(\beta_{l}, \beta_{k}, \eta, \beta_{e}, \boldsymbol{\beta}_{x}\right)$.

The presence of the demand shocks $u_{j t}^{d}$ in $\epsilon_{j t}$ adds possible endogeneity concerns regarding large store entrants, local market output, and wages (i.e., the moments $E\left[\epsilon_{j t} \mid e_{m t}^{L}, q_{m t}, w_{j t}\right]=0$ does not hold). To obtain the estimate $\hat{\phi}$ from (8), we use the Two-Stage Least Squares (2SLS) estimator and the moment conditions $E\left[\epsilon_{j t} \mid f\left(l_{j t}, w_{j t-1}, k_{j t}, q_{m t-1}, \sum_{o \neq m} q_{o t}, e_{m t-1}^{L}, \sum_{o \neq m} e_{o t}^{L}\right.\right.$,

\footnotetext{
${ }^{29}$ In the absence of store-level wages, however, it may be difficult to estimate the coefficients of static inputs in the Cobb-Douglas case (Bond and Söderbom, 2005). The proposed estimation strategy assumes that the first-order condition for labor does not include the derivative of the wage rate with respect to labor.
} 
$\left.\left.p l_{m t}, \mathbf{x}_{m t}\right)\right]=0, \quad t=1, \cdots, T$, where $f$ is vector-valued instrument functions (Wooldridge, 2009), $\sum_{o \neq m} q_{o t}$ is the aggregate quantity in the neighborhood local markets, $\sum_{o \neq m} e_{o t}^{L}$ is the number of large entrants in the neighborhood local markets. The robustness section shows and discusses the estimates without controlling for endogeneity using the Ordinary Least Squares (OLS) estimator, as in OP the framework.

As noted, retail groups can decide into enter large stores in markets with favorable characteristics, such as a short distance to a distribution center or good logistics. In other words, the moment condition $E\left[\epsilon_{j t} \mid e_{m t}^{L}\right]=0$ does not hold when $\epsilon_{j t}$ includes shocks due to advertising, sales promotion activities related to large store entrants, and distribution (transportation). To account for the endogeneity of large store entrants, we use the share of non-socialist seats in local governments (Bertrand and Kramarz, 2002; Schivardi and Viviano, 2011; Maican and Orth, 2015), the number of large store entrants in other markets (Hausman-type instruments), and the previous number of large store entrants as instruments. ${ }^{30}$ Local authorities make decisions regarding entry, and we expect non-socialist local governments to have more liberal views regarding large store entrants. ${ }^{31}$

The remaining demand shocks in $\epsilon_{j t}$ affect stores differently and might also impact the aggregate service output making the moment $E\left[\epsilon_{j t} \mid q_{m t}\right]=0$ not hold. Our local market approach differs from that of De Loecker (2011), who considers firms that are relatively small relative to the industry. Still, median local markets consist of approximately 15 stores that independently

\footnotetext{
${ }^{30}$ Data on the number of applications and rejections for each municipality are not available in Sweden. Even if this information were available, it would not be completely exogenous because the number of applications is easily influenced by current local government policies. No major policy reforms changing the conditions for large store entrants occurred in Sweden during the study period. Hausman-type instruments are widely used, as they are always available, but their use is controversial (Hausman, 1997).

${ }^{31}$ The Social Democratic Party is the largest party nationally, with 40.6 percent of seats on average. It collaborates with the Left Party ( 8 percent) and the Green Party (4.2 percent). The non-socialist group consists of the Moderate Party (18 percent), which is most often aligned with the Center Party (13.2 percent), the Christian Democratic Party (5.9 percent), and the Liberal Party (5.6 percent). Twenty-two percent of municipalities had a non-socialist majority during the period 1996-1998, increasing to 32 percent during 1999-2002. The non-socialists had 8.6-85 percent and averaged 40.7 percent in 1996-1998 and 44.1 percent in 1999-2002.
} 
make price decisions. To control for possible endogeneity of market output, i.e., correlation between $q_{m t}$ and $u_{j t}^{d}$, previous market output or market output in other local markets can be used as instruments for $q_{m t}$. When $\epsilon_{j t}$ include demand shocks related to wages, then $E\left[\epsilon_{j t} \mid w_{j t}\right]=0$ does not hold and the moment $E\left[\epsilon_{j t} \mid w_{j t-1}\right]=0$ can be used in estimation. ${ }^{32}$ The empirical implementation and results sections offer additional discussions and specific tests on the instruments for large store entrants and local market quantity.

Selection. Store decisions to exit in period $t$ depend directly on $\omega_{j t}$; therefore, the decision is correlated with the productivity shock $\xi_{j t}$ (Olley and Pakes, 1996). Selection can affect retail markets because large stores (large $k_{j t}$ ) are more likely to survive larger negative productivity shocks than are small stores. Even if stores have low productivity, there might be other reasons for stores to stay active such as favorable market conditions, logistics support by the firm, and a good location. To control for selection when estimating the service-generating function, we use predicted survival probabilities $\mathscr{P}_{j t}$ (Olley and Pakes, 1996). ${ }^{33}$ In the estimation, selection affects only the productivity process in the OP approach, i.e., $\omega_{j t}=h\left(\omega_{j t-1}, e_{m t-1}^{L}, \mathscr{P}_{j t}\right)+\xi_{j t}$.

Estimation of service-generating function parameters. In the second step, we nonparametrically regress $\omega_{j t}(\boldsymbol{\beta})$ on a polynomial expansion of order three in $\omega_{j t-1}(\boldsymbol{\beta}), e_{m t-1}^{L}$, and $\mathscr{P}_{j t}$. To identify $\boldsymbol{\beta}$, the following moment conditions based on productivity shocks $\xi_{j t}$ that are directly linked to the model in Section 3 can be used, i.e., $E\left[\xi_{j t} \mid l_{j t-1}, k_{j t-1}, e_{m t}^{L}, q_{m t-1}, \mathbf{x}_{j t-1}\right]=$ 0 (i.e., just-identified specification). This set of moments uses the timing assumption for large entry, i.e., large store entrants influence productivity with a one-year lag, and only current large entrants influence prices, which implies that we can use the moment $E\left[\xi_{j t} \mid e_{m t}^{L}\right]=0$. Adding $p l_{m t-1}$

\footnotetext{
${ }^{32}$ If the observed variation in store wages is due to differences in exogenous market conditions, the moment condition $E\left[\epsilon_{j t} \mid w_{j t}\right]=0$ can be used in the estimation (Ackerberg et al., 2007).

${ }^{33}$ Probability of being in the data in period $t$ conditional on the information in $t-1$ is given by $\operatorname{Pr}\left(\chi_{j t}=1 \mid \underline{\omega}_{m t}, \mathcal{F}_{t-1}\right)=\operatorname{Pr}\left(\omega_{j t} \geq \underline{\omega}_{m t} \mid \underline{\omega}_{m t}, \mathcal{F}_{t-1}\right)=$ $P_{j t}\left(l_{j t-1}, k_{j t-1}, w_{j t-1}, p_{m t-1}, q_{m t-1}, e_{m t-1}^{L}, \mathbf{x}_{m t-1}\right) \equiv \mathscr{P}_{j t}$, where the second equality follows from the inverse of the labor demand function.
} 
and $\sum_{o \neq m} e_{o t-1}^{L}$ as instruments gives us an overidentified specification. We use this overidentified specification to obtain the main results in Section 6. The robustness of our results when using alternative moment conditions are discussed in Section 6.5. ${ }^{34}$

The parameters $\boldsymbol{\beta}$ are estimated by minimizing the GMM objective function

$$
\min _{\boldsymbol{\beta}} Q_{N}=\left[\frac{1}{N} W^{\prime} \xi(\boldsymbol{\beta})\right]^{\prime} A\left[\frac{1}{N} W^{\prime} \xi(\boldsymbol{\beta})\right],
$$

where $A$ is the weighting matrix defined as $A=\left[\frac{1}{N} W^{\prime} \xi(\boldsymbol{\beta}) \xi^{\prime}(\boldsymbol{\beta}) W\right]^{-1}$, and $W$ is the matrix of instruments. ${ }^{35}$ The estimation is performed at the industry level, controlling for local market conditions. Standard errors are computed according to Ackerberg et al. (2012). ${ }^{36}$

\subsection{Additional remarks on the timing assumption of large store entrants}

In the following, we discuss how the timing assumption on large store entrants affects the marginal effect of one additional large store entrant on incumbent productivity. We show that the presence of demand shocks related to large store entrants to productivity measures produces a downward bias in the effect of the large store entrants on productivity. However, read-

\footnotetext{
${ }^{34}$ When the moment $E\left[\xi_{j t} \mid e_{m t}^{L}\right]=0$ does not hold, an overidentified specification based on the set of moments $E\left[\xi_{j t} \mid l_{j t-1}, k_{j t-1}, p o l_{m t-1}, \sum_{o \neq m} e_{o t-1}^{L}, q_{m t-1}, \mathbf{x}_{j t-1}\right]=0$ can be used to identify $\boldsymbol{\beta}$ (see Section 6.5). As Ackerberg et al. (2015) discuss in their Section 4.1., there are many ways to estimate an Olley and Pakes' framework based on second step moments. For example, one can also use the moment conditions based on $\xi_{j t}+\epsilon_{j t}$ (see also the discussion in Gandhi et al., 2014). It is also important to emphasize that stronger assumptions can lead to more precise estimates.

${ }^{35}$ Wooldridge (2009) and Ackerberg et al. (2015) [ACF] (equation (31)) suggest a onestep estimator using GMM based on moment conditions $E\left[\epsilon_{j t} \mid \mathcal{F}_{j t}\right]=0$ and $E\left[\left(1+\frac{1}{\eta}\right) \xi_{j t}+\right.$ $\left.\epsilon_{j t} \mid \mathcal{F}_{j t-1}\right]=0$. Even if this estimator is more efficient than the two-step estimator, it is very computationally demanding in our case due to the large number of parameters to be estimated.

${ }^{36}$ Bootstrapping might not be the best choice when the underlying model is more complicated. It requires additional computation time, optimization errors may appear, and the choice of stores in different samples yields different effects of competition from large store entrants, which implies that a large number of bootstraps may be required.
} 
ers not interested in these details can go directly to the empirical results.

Empirical evidence. In our setting, large store entrants immediately affect stores' residual demand and thus local market equilibrium prices but affect store productivity with a one-year lag. Reduced-form evidence shows that this assumption is not rejected by our data; e.g., when regressing store sales or value-added on both $e_{m t}^{L}$ and $e_{m t-1}^{L}$, the coefficient on lagged large store entrants is not significant using OLS or 2SLS estimators. Most importantly, the coefficient for $e_{m t-1}^{L}$ is positive in all of the regressions, i.e., our hypothesis is not rejected. ${ }^{37}$ Therefore, the findings suggest that we cannot reject the timing assumption regarding the number of large store entrants. However, this reduced-form empirical evidence on the timing assumption should be interpreted with care, as the regressions do not control for other simultaneity and selection bias issues (specific to production functions).

Measurement issues. If $u_{j t}^{d}$ are i.i.d. shocks (i.e., not part of $\omega_{j t}$ ), we can use the timing assumption on large store entrants to separate the impact of large store entrants on productivity from their impact on demand (De Loecker, 2011). To show the implications of the timing assumption, we consider the total change in future productivity given by the Markov process, i.e., $d \omega_{j t}=h_{\omega} d \omega_{j t-1}+h_{e^{L}} d e_{m t-1}^{L}$, where $h_{\omega}=\partial h(\cdot) / \partial \omega_{j t-1}$ is the marginal effect of the previous productivity $\left(\omega_{j t-1}\right)$ on future productivity $\left(\omega_{j t}\right)$ and $h_{e^{L}}=\partial h(\cdot) / \partial e_{m t-1}^{L}$ is the marginal effect of an additional large store entrant $\left(e_{m t-1}^{L}\right)$ on future productivity $\left(\omega_{j t}\right) .{ }^{38}$ Thus, the total change in productivity in period $t$ due to the number of large store entrants in $t-1$ is $d \omega_{j t} / d e_{m t-1}^{L}=h_{\omega} \times\left(d \omega_{j t-1} / d e_{m t-1}^{L}\right)+h_{e^{L}}$. Our timing assumption on large store entrants implies that the immediate effect of large store entrants on productivity is zero, $d \omega_{j t-1} / d e_{m t-1}^{L}=0$, which yields $d \omega_{j t} / d e_{m t-1}^{L}=h_{e^{L}}$.

\footnotetext{
${ }^{37}$ Online appendix B provides a detailed discussion of the identification of the effect of large store entrants on productivity and demand, and Tables B.2-3 present reduced-form results. The share of non-socialist seats and the number of large stores in neighboring municipalities are used as instruments to control for endogeneity of the current number of large store entrants $\left(e_{m t}^{L}\right)$.

${ }^{38}$ We use the continuous notation because store productivity is a continuous variable, and it interacts with the number of large store entrants. In the case of a discrete variable, the partial derivative is in fact the first difference,i.e., $\frac{\partial \omega_{j t}}{\partial e_{m t-1}^{L}}=\frac{\partial h(\cdot)}{\partial e_{m t-1}^{L}} \simeq$ $\left[h\left(\omega_{j t-1}, e_{m t-1}^{L}+1\right)-h\left(\omega_{j t-1}, e_{m t-1}^{L}\right)\right] \equiv \Delta_{e^{L}} h\left(\omega_{j t-1}, e_{m t-1}^{L}\right)$.
} 
The remaining demand shocks $u_{j t}^{d}$ are less likely to be mean-independent of current and previous numbers of large store entrants when we do not control for the effect of large store entrants on demand. If this is the case, the shocks $u_{j t}^{d}$ are related to large store entrants, and they will be part of the productivity measure. To understand the measurement implications for the impact of large store entrants on productivity, we denote by $\tilde{\omega}_{j t}$ the productivity measure that includes residual demand shocks related to large store entrants, $\tilde{\omega}_{j t}=\omega_{j t}-(1 /(1+\eta)) u_{j t}^{d}$.

An increase in the number of large store entrants in the market implies lower residual demand, i.e., $\left(d u_{j t}^{d} / d e_{m t}^{L}\right)<0$. Using simple algebra, we find that the impact of large store entrants on a productivity measure affected by demand shocks related to large store entrants $\left(\tilde{\omega}_{j t}\right)$ is lower than that on $\omega_{j t}$, i.e., $\left(d \tilde{\omega}_{j t} / d e_{m t-1}^{L}\right)<\left(d \omega_{j t} / d e_{m t-1}^{L}\right) .{ }^{39}$ Therefore, not fully controlling for the impact of large store entrants on demand results in a downward bias in the effect of large store entrants on productivity.

The downward bias in the effect of large store entrants on productivity also results if $u_{j t}^{d}$ are correlated over time after various controls as well as part of a store's input and exit decisions. In this case, we can only identify the impact of large store entrants on $\tilde{\omega}_{j t}$. To address only one unobservable, the implicit assumption in the empirical implementation is that the productivity measure is $\tilde{\omega}_{j t}$, which follows a Markov process. In this case, the remaining i.i.d. shocks are denoted by $\epsilon_{j t}=\left(1+\frac{1}{\eta}\right) u_{j t}^{p}$. Summarizing, the key difference between the impact of large store entrants on $\tilde{\omega}_{j t}$ and $\omega_{j t}$ is that the effect is lower on the productivity measure that includes demand shocks, $\tilde{\omega}_{j t}{ }^{40}$

${ }^{39}$ This result occurs because $\frac{d \tilde{\omega}_{j t}}{d e_{m t-1}^{L}}=-\frac{1}{1+\eta} h_{\tilde{\omega}} \frac{d u_{j t-1}^{d}}{d e_{m t-1}^{L}}+h_{e^{L}}<h_{e^{L}} \equiv \frac{d \omega_{j t}}{d e_{m t-1}^{L}}$. In addition, this result also occurs when both current and previous numbers of large store entrants have an effect on demand, but we do not control for the effect from previous entrants on demand in the estimation, i.e., $\left(d u_{j t}^{d} / d e_{m t}^{L}\right)=0$ and $\left(d u_{j t}^{d} / d e_{m t-1}^{L}\right)<0$. In this case, the impact of a large store entrant on productivity is $\frac{d \tilde{\omega}_{j t}}{d e_{m t-1}^{L}}=\frac{d \omega_{j t}}{d e_{m t-1}^{L}}-$ $\frac{1}{1+\eta} \frac{d u_{j t}^{d}}{d e_{m t-1}^{L}}<\frac{d \omega_{j t}}{d e_{m t-1}^{L}}$.

${ }^{40}$ The productivity measure can also be affected by capital mismeasurement, e.g., stores vary their capital services by changing their utilization of the capital stock, or capital service flows for retail space might be higher in urban/dense areas than in typical big-box locations. Because these data are not available, we assume that the flow of 
If we had price data for each store, we could estimate demand and supply separately, which would allow us to distinguish between the impact of large store entrants on demand and on supply without relying on a timing assumption. However, the retail market is complex due to its multistore, multi-product, and multi-location nature. Owing to this complexity and difficulties in defining a "price" measure (because stores offer different product baskets), this type of analysis of retail markets will always require additional assumptions (e.g., a timing assumption) to separately identify the effect of large stores on demand and on supply. Hence, even if prices are observed, the use of a product basket necessitates assumptions. In fact, the researcher will have to choose among sets of assumptions in accordance with the specific application and data available.

\subsection{Empirical implementation}

Wage variation. Helpful variation in store-specific wages is required when using labor demand to recover store productivity. ${ }^{41}$ High-quality data on store-specific wages, the fact that stores set wages, and the prevalence of temporary job contracts and part-time work ensure the existence of wage variation across stores. The coefficient of variation for wages is approximately 18 percent across stores and 53 percent across municipalities. Store-

equipment services is proportional to the stock of equipment (ideally, we would like to know how each machinery (technology) and square meter of sales space are used in the store). We minimize capital mismeasurements by controlling for the common characteristics of capital service flows for retail space at the local market level.

${ }^{41}$ Our measure of wages is a good reflection of exogenous changes in the price of labor because the 22 percent growth in the retail wage bill during the period (Table 1 ) is consistent with the 24 percent growth in aggregate real wages in Sweden (Statistics Sweden). The average wage contains both the price of labor and its composition, e.g., age, gender, and skill groups. In Sweden, we do not expect compositional effects due to some employees working overtime or differences in opening hours across stores. The one-sided t-test results show that we cannot reject the null of equal means of the share of educated employees (0.064) for both small and large stores. However, wages might pick up unobserved worker quality. Because worker quality is unobserved by the econometrician but observed by stores, we have two unobservables to control for, which complicates estimation. Instead, the unobserved quality will enter into our productivity measure. However, this concern is not significant in the retail food market, where the quality of workers is expected to be fairly homogeneous (online appendix C). 
specific wages regressed on market- and year-fixed effects, store size, and observed labor quality (education) show that there are other unobserved factors at the store level, for example, bargaining negotiations, experience, etc., that explain variations in store wages (online appendix $\mathrm{C}$ ).

Using data for the year 2000, market dummy variables alone explain only 9.7 percent of the variation in wages. By adding capital and a dummy for large stores and local market controls, we explain 14.2 percent of the wage variation. By including the number of employees as an additional measure of store size, the variation in wages explained by the covariates increases to 15.7 percent.

Instruments for large entrants. In the following text, we elaborate more on the use of the proposed instruments for large store entrants. To be an effective instrument for large store entrants, political preferences (i.e., the share of non-socialist seats) should not be related to local market demand or reflect characteristics of the population that favor shopping at big-box stores but can boost productivity at other stores. This approach raises the following concerns. First, the outcomes of elections might be influenced by economic conditions. Political business cycles can only affect our results if there is substantial ability to predict future demand shocks when politicians are elected. We also investigate median local market characteristics for socialist markets with large store entrants and non-socialist markets without large store entrants. There are between 1-6 socialist markets with large store entrants and 82 to 147 non-socialist markets without large store entrants during the study period. Socialist markets with large store entrants are larger markets (population) and have lower population density than non-socialist markets without large store entrants. In addition, these two groups of markets do not significantly differ in income per capita. Importantly, we control for local market characteristics (income growth, population growth, population density) when estimating productivity.

The second concern is that political preferences might capture local policies other than entry regulations. In Sweden, the PBA is rather exceptional because it enables local politicians to play a key role. Furthermore, 
in our context, the number of large store entrants in other markets is an appropriate instrument if the number of large store entrants in other markets reflects common trends or demand shocks that are only specific to large store entrants, e.g., unobserved advertising.

Although the proposed instruments are not perfect when there are correlated unobservables across markets, we believe that they are the best instruments, given the available data and modeling framework, and they have been used extensively in the empirical literature. Section 6.1 presents the statistical specification tests on the instruments when estimating the model.

Large store entrants. The choice to model the entry of new large stores instead of the total number of large incumbents is due to the entry regulation's focus on entrants' impact on consumers and the market structure. We also focus on the fact that new stores come with new technology and innovations, providing a one-time learning opportunity for incumbents. For instance, scanner techniques have become common among large store entrants in recent years. ${ }^{42}$

Demand system. Although our CES demand model is restrictive because of data constraints, several features make it less restrictive in the Swedish retail food market than in many other industries. First, stores determine their own prices, and we do not expect a single store to influence the market price because local markets contain many stores. On average, there are 30 stores in markets with large store entrants and 15 in markets without large store entrants (Table 3). Second, all stores offer a wide range of products, i.e., we assume that stores serve the same basic function for consumers - to provide food. In Sweden, price (and quality) differences for a homogenous product basket are found to be small between groups and stores (Asplund and Friberg, 2002). Given our data constraints, we focus on the key dimension of differentiation in location.

Store price decision. Stores adjust their prices in response to a large store entrant, and this change most likely occurs within the year that large

\footnotetext{
${ }^{42}$ The modeling implications of using the existence of large stores instead of their entry is explained in footnote 17 . Specifically, it implies that we need to lag the data twice, which is not preferable for our short panel.
} 
store entry takes place. In Sweden, individual stores make pricing decisions and previous research on Swedish data has documented that large store entrants have only small effects on the prices of rival stores (Asplund and Friberg, 2002). ${ }^{43}$ The cost of adjusting prices is low, and there is a high frequency of price changes to retail food products (we abstract from promotions and discounts, etc.). Our model captures the average price effect in the year of entry, i.e., the main shift in price that may occur after large store entry. We argue that this is a valid time period in which to measure the "main demand response" as a consequence of large store entry.

\section{Results}

This section presents the main empirical results from the model presented in Section 3. First, we discuss the estimation of the service-generating function that allows us to recover store productivity. Then we discuss how large store entrants affect store productivity, aggregated weighed productivity in local markets, and exit.

Our main specification is the most general one that (i) controls for simultaneity and selection biases; (ii) allows the external environment of stores to affect productivity, i.e., the previous number of large store entrants affects the productivity process; (iii) allows for imperfect competition, where current large store entrants and other local market characteristics affect demand; and (iv) controls for endogeneity of large store entrants, aggregate market demand and wages (see Section 5). Section 6.5 considers alternative modeling specifications and discusses several robustness checks.

\footnotetext{
${ }^{43}$ If we aggregate and analyze decisions of, e.g., pricing at the firm level (instead of at the store level), we lose much of the dynamics crucial to our analysis of the Swedish retail food market. National pricing with the market power of groups rather than stores is more common in other countries (e.g., the U.K.). To analyze the relationship between groups and stores in more detail, we would require data on the identity of (multi-) stores for which we observe inputs and outputs. The decision to exit or continue is made at the store level, although groups can influence each store's decision through possible chain effects. Section 2 provides details regarding the organization of groups.
} 


\subsection{Service-generating function estimates}

Table 4 presents estimates of the service-generating function. We show the results from the OLS estimator under perfect competition (column 1) and the two-step estimator presented in Section 5. Column (2) shows the estimates that include elasticity, and column (3) shows the estimates without elasticity (i.e., structural parameters). ${ }^{44}$

The estimate for the labor coefficient augmented by demand elasticity is 0.406 and that for capital is 0.188 (column (2)). The corresponding structural parameters (without elasticity, i.e., $\beta_{l}$ and $\beta_{k}$ ) are 0.797 for labor and 0.368 for capital. As theory suggests, the estimate of returns to scale $\left(\beta_{l}+\beta_{k}\right)$ in our estimator that controls for imperfect competition is greater (1.165) than that under perfect competition given by the OLS results (0.929). Few studies that use a production function framework emphasize the returns to scale in service industries. Increasing returns to scale are expected in industries with high consumer participation, geographic dispersion, and multi-market contacts (economies of density). The scale is likely to increase with the degree of self-service and is found to be higher in retail food than in other retail sectors (Ofer, 1973). ${ }^{45}$ The Sargan test shows that the overidentifying instruments used to estimate $\boldsymbol{\beta}$ are valid, i.e., the test fails to reject the null hypothesis that the instruments are uncorrelated with the productivity shocks $\xi_{j t}(p$-value $=0.985)$.

The estimate of the implied elasticity of demand is -2.04 . Thus, the implicit assumption that $\eta=-\infty$, which is often used in empirical studies, does not hold. The markup, defined as price over marginal cost, is 1.95. Our estimates are consistent with previous findings based on retail data

\footnotetext{
${ }^{44}$ Physical quantity cannot be measured in service industries; therefore, we report the coefficients of the value-added function augmented by demand elasticity in column (2), i.e., $(1+1 / \eta) \beta_{k}$ and $(1+1 / \eta) \beta_{l}$. This reporting approach also allows for easy reading across different reduced-form estimators, for example, OLS.

${ }^{45}$ For food retailing in Israel, Ofer (1973) estimates returns to scale at 1.42 and at 1.31 when controlling for supermarkets. Bairam (1994) estimates returns to scale at approximately 1.30 for fruits and vegetables based on Australian data. These estimates rely on Cobb-Douglas technology and value-added but do not control for simultaneity, selection or omitted price bias. As shown in the previous version of the paper, the scale is larger when including large cities in the estimation (Stockholm, Göteborg, and Malmö).
} 
(Hall, 1988; Roeger, 1995; Maican and Orth, 2013). ${ }^{46}$

Large store entrants have an expected negative effect on residual demand and, hence, prices in the year of entry. An additional large store entrant decreases residual demand by, on average, 0.2 percent, but the effect is not statistically significant. That large stores have a modest impact on residual demand and hence prices is consistent with previous studies on the Swedish retail food market (Asplund and Friberg, 2002). Stores in markets with growing population or income have a higher residual demand. However, stores in densely populated markets have a lower residual demand. This finding links to previous work indicating that markets with high population density are more competitive (Syverson, 2004).

First-stage results. The results of the first-step estimation of the salesgenerating function (equation (8)) are presented below. Readers not interested in these details can turn directly to the estimates of the productivity process (Section 6.2).

To control for possible endogeneity of large store entrants $\left(e_{m t}^{L}\right)$, aggregate market output $\left(q_{m t}\right)$, and wages $\left(w_{j t}\right)$ when recovering productivity, we estimate equation (8) using the 2SLS estimator. Political preferences, previous number of large store entrants, number of large store entrants in the neighborhood markets, and previous local market output and wages are used as instruments for $e_{m t}^{L}, q_{m t}$, and $w_{j t}$. Because of the polynomial expansion and large state space, equation (8) contains many parameters; for simplicity, we only discuss specification tests in the main text and do not show first-stage estimates from 2SLS.

The Sargan test of overidentifying restrictions fails to reject the null hypothesis that the instruments are uncorrelated with the residuals $(p$ value $=0.09)$, and we conclude that the overidentifying instruments are

\footnotetext{
${ }^{46}$ The aggregate mark-up $(\eta /(1+\eta))$ depends on the estimated elasticity of demand $\eta$ at the industry level; i.e., a larger $|\eta|$ implies a lower mark-up. Hall (1988) uses aggregate sector time series U.S. data and finds a markup of approximately 1.42 for retail trade and 1.53 for services. Using the same data, Roeger (1995) finds a markup of approximately 1.50 for food and kindred products. Using a nested logit demand model with store-level prices for a product basket in Swedish retail food (2001-2008) and assuming Nash equilibrium, Maican and Orth (2013) find an estimated average price elasticity of approximately -3 for large stores and -3.8 for small stores.
} 
valid. To check the validity of the instruments, we report the partial $F$-test suggested by Staiger and Stock (1997) (Table 4). The statistically significant $F$-tests validate the proposed instruments and show that they are not weakly correlated with the number of large store entrants, local market output, and wages. The partial $F$-tests when considering each potential endogenous variable are larger than 10 (Stainer and Stock's threshold), i.e., for large store entrants, $F$-value $=65.66$; for local market output, $F$ value $=216.05$; and for wages $F$-value $=85.93$.

To ensure the relevance of our instruments, we also run simple reducedform regressions outside of our two-step framework. The findings are summarized here, and they are reported and discussed in detail in online appendix B. The findings show that the share of non-socialist seats in local markets and the number of large store entrants in other municipalities in the same county (neighboring markets) have a positive and statistically significant effect on the number of large store entrants after controlling for observed and unobserved market characteristics. Using simple reducedform regressions with various controls, we also find that previous aggregate market output and previous wages have a positive and statistically significant effect on current aggregate market output and wages, respectively. In addition, we should recall that the only objective of the first-step in our structural framework is to isolate demand shocks from the productivity measure (lower prices, new demand from product differentiation) associated with current large store entrants.

\subsection{Store productivity and large store entrants}

In this section, we discuss the main findings on how large store entrants influence store productivity. Using the estimated parameters of the servicegenerating function and equation (9), we recover store productivity without i.i.d. shocks. ${ }^{47}$

\footnotetext{
${ }^{47}$ Productivity can also be recovered from the service-generating function: $\omega_{j t}=$ $\frac{\eta}{1+\eta}\left[y_{j t}-\left(1+\frac{1}{\eta}\right)\left[\beta_{l} l_{j t}+\beta_{k} k_{j t}\right]+\frac{1}{\eta} q_{m t}+\frac{1}{\eta} \beta_{e} e_{m t}^{L}+\frac{1}{\eta} \mathbf{x}_{m t}^{\prime} \boldsymbol{\beta}_{x}\right]$. However, this productivity measure contains the i.i.d. $\epsilon_{j t}$ shocks. Our results on the impact of large store entrants
} 
To highlight descriptive patterns in the productivity distributions in local markets, incumbents are classified into six percentile bins (p10, p1025, p25-50, p50-75, p75-90, p90) for each year based on productivity. We then follow transitions between percentile bins or exit over time. Table 5 shows that low-productivity incumbents in markets without large store entry decrease their productivity or stay as low-productivity stores without being forced to exit. The share of incumbents that remain in p10 is 10 percentage points higher in markets without large store entry. Stores with low productivity are small, i.e., they have fewer employees, lower capital stock, and lower value-added.

The estimation of a simple linear $A R(1)$ productivity process shows that an additional large store entrant increases store productivity by 2.4 percent. While an exogenous $A R(1)$ process is not entirely consistent with our structural model, these results provide the first evidence of a positive effect of large store entrants on store productivity. These findings also show high persistence of productivity. ${ }^{48}$

\subsubsection{Main results}

Our structural framework provides information about stores' heterogeneous productivity responses with respect to large store entrants through the estimation of the nonlinear productivity process. The conditional expectation of future productivity, $h\left(\omega_{j t-1}, e_{m t-1}^{L}, \mathscr{P}_{j t}\right)$, is approximated using a third-order polynomial expansion in its arguments (Table 6). ${ }^{49}$ Large store

on productivity are robust to using this alternative measure. The average productivities obtained from both measures (output and proxy) are close, but there are distributional differences and, as expected, a higher variance when using the service-generating function. For our preferred specification, the interquantile ranges are 1.192 and 1.438 for productivity recovered from labor demand and output, respectively.

48

$$
\omega_{j t}=\underset{(0.005)}{0.710 \omega_{j t-1}}+\underset{(0.012)}{0.024 e_{m t-1}^{L}}+\xi_{j t}, \quad \mathrm{R}^{2}=0.630
$$

(standard errors are in parentheses). In the absence of large store entrants and other productivity shocks, 71 percent of actual productivity comes from previous productivity.

${ }^{49}$ The static entry process implies that there is no endogeneity problem of large store entrants in the productivity process because $e_{m t-1}^{L}$ is uncorrelated with current 
entrants can influence productivity differently depending on store productivity $\omega_{j t-1}$ and $e_{m t-1}^{L}$. Therefore, a gain is that we recover marginal effects of large store entrants on productivity for each store in the data set. We can then exploit heterogeneity in store productivity responses to large store entrants in multiple dimensions. We only consider incumbent stores and exclude stores that enter (see next section for exit). For brevity, we focus on marginal effects and specification tests in the main text.

Summary of store productivity responses. Table 6 shows the productivity changes from an additional large store entrant across all incumbent stores in Sweden (the three largest cities are excluded). ${ }^{50}$ The median increase in incumbent productivity from a large store entrant is 3.1 percent. There is also substantial heterogeneity in the magnitudes across stores at the national level. The interquartile range of the distribution of the marginal effects is 2.7 percent. ${ }^{51}$ The 75 th percentile marginal effect (4 percent) is approximately three times larger than that at the 25 th percentile (1.3 percent). The estimation of the controlled productivity process shows that an average store has higher persistency in productivity than when using the simple exogenous $A R(1)$ specification (nonlinear controlled: 0.745; $A R(1)$ : 0.710). The findings also show that the remaining productivity shocks $\left(\xi_{j t}\right)$ have a lower variance in the nonlinear specification than in $A R(1)$.

Productivity regression: specification tests. We perform $F$-tests of the null hypotheses of zero coefficients for all terms in the productivity process that include store productivity and the number of large store entrants. The null is rejected for both productivity $(F$-test $=7.9, p$-value $=0.000)$ and large store entrants $(F$-test $=3632.8, p$-value $=0.000)$. All coefficients of the polynomial expansion are reported in online appendix D.

innovation in productivity $\xi_{j t}$ (Section 3 ). We model $e_{m t-1}^{L}$ as a continuous variable in the Markov process because $e_{m t-1}^{L}$ is larger than one in some local markets (see also footnote 38 ). The results remain robust when using a dummy variable for the entry of large stores.

${ }^{50}$ By including the three largest cities, Stockholm, Göteborg, and Malmö, the positive impact of large store entrants on productivity is approximately 1-2 percent greater.

${ }^{51}$ Because of exit and product differentiation, this result does not imply that large store entrants will continuously increase productivity among incumbents. 
Productivity distribution in local markets. Focusing on local markets, we evaluate whether large store entrants have a greater impact on one part of the productivity distribution than another. Table 7 (Panel A) shows the marginal effects of large store entrants related to incumbents' position in the local market productivity distribution. To account for store productivity heterogeneity when measuring the impact of large store entrants across local markets, we evaluate the marginal effects of an additional large store entrant for different productivity percentiles at the local market level (10th, 25th, 50th, 75th, and 90th). First, we calculate the marginal effects of large store entrants for each productivity percentile measure in each local market. Second, we compute the median and standard deviation of the marginal effects for each productivity percentile measure across local markets. This approach provides us with robust productivity changes across local markets following entry by a large store for each productivity percentile.

The median increase in store productivity from an additional large store entrant across local markets is 4 percent. There is, however, high dispersion in the impact across markets, as indicated by the standard deviation of 0.076. A key result is that the impact of large store entrants on productivity decreases toward the upper parts of the productivity distribution. Large store entrants force low-productivity incumbents to improve their productivity more than high-productivity incumbents. A large store entrant increases productivity by 2 percentage points more for a store in the 10th local market productivity percentile than for a store in the 90th percentile. The corresponding difference is 1 percentage point for a store in the 25 th productivity percentile compared with a store in the 75 th percentile.

Variation in the number of large store entrants across local markets creates differences in competitiveness and in store incentives to improve productivity. Increasing competition reduces productivity dispersion in local markets, and our findings are in line with the recent empirical literature on productivity (Syverson, 2004; Asplund and Nocke, 2006; Collard-Wexler, 2011). This result occurs because low-productivity stores have stronger incentives to reduce costs and slack to continue to operate than do high- 
productivity stores. Thus, the lower tail of the local productivity distribution moves faster than the upper tail as a result of increased competitiveness. Recognizing that stores are heterogeneous in their productivity response to large store entrants allows us to understand the productivity differences across local markets (Syverson, 2011).

Heterogeneity by ownership. To further exploit store heterogeneity, we examine whether the store productivity changes resulting from large store entrants vary by ownership structure in local markets. Interestingly, the productivity gains from large store entrants are higher if more retail groups operate in the local market. The median increase in store productivity is 2.3 percent in markets with two groups and 2.8 percent in markets with three groups. The corresponding figures are 3 and 3.2 percent for markets with four and five groups, respectively. Furthermore, the interquantile range in the impact of large store entrants is smaller in markets with many groups, e.g., 0.037 and 0.026 in markets with two and five groups, respectively.

Further, the increases in store productivity due to a large store entrant are positively correlated with the joint market shares of stores affiliated with ICA (i.e., the market share of the ICA group) in the municipality but are negatively correlated with the market share of Coop. The Coop group started to reorganize their store formats after 2002. These results reflect differences in store productivity changes from large store entry across groups and ownership structures in local markets. ${ }^{52}$

\footnotetext{
${ }^{52}$ It is important to highlight that these results are only descriptive statistics of the impact of large store entrants on store productivity conditional on group affiliation and the market shares of groups in local markets. However, we do not explicitly model the affiliation of stores with groups in our single agent dynamic framework. The number of groups and the market shares of stores affiliated with different groups are constructed using DELFI. Anonymous identification codes hinder us from obtaining group affiliates of stores in the SCB data, which provide inputs and outputs for our productivity estimation.
} 


\subsubsection{Aggregate productivity in local markets}

Policymakers making decisions about the entry of new stores need to consider the responses of all of the incumbents in local markets. For an overall cost-benefit analysis of allowing large new stores to enter a local market, it is important to evaluate the changes in aggregate productivity due to the large store entrants.

Aggregate productivity in market $m$ is $\omega_{m t}=\sum_{j=1}^{n_{m}} s_{j t} \omega_{j t}$, where $s_{j t}$ is the market share of store $j$ in period $t$ and $n_{m}$ is the number of stores. We compute the change in aggregate local market productivity due to a large store entrant as a weighted sum of individual stores' marginal effects using store market shares as weights, i.e., $\sum_{j=1}^{n_{m}} s_{j t} \frac{\partial h(\cdot)}{\partial e_{m t-1}^{L}} .{ }^{53}$ As before, we only focus on changes in the productivity of incumbent stores.

Table 7 (Panel B) shows the distribution of the weighted aggregate local market productivity growth of incumbents following a large store entrant, i.e., $\sum_{j=1}^{n_{m}} s_{j t} \frac{\partial h(\cdot)}{\partial e_{m t-1}^{L}}$. The median contribution of a large store entrant to the local market productivity growth of incumbents is 1.5 percent, with a maximum of 3.4 percent. These figures are 2.5 percentage points lower than the median increase in productivity computed using distribution measures of local market productivity reported as averages across markets (4 percent - Panel A in Table 7). There are at least two possible explanations for this results. It is likely that stores with relatively low productivity increases from a large store entrant have larger market shares and therefore receive larger weights. It could also be that more stores have low productivity increases rather than high productivity increases from a large store entrant (marginal effect).

Heterogeneity by market size. We also consider the relationship between productivity and market size. The average aggregated weighted local market productivity is the same in small and large markets (1.4 percent). However, the dispersion (measured by the interquantile range) is lower in large markets, i.e., 0.020 in small markets and 0.014 in large markets. The

\footnotetext{
${ }^{53}$ We do not model the changes in market shares due to large store entrants. To model the impact of large store entrants on market share in various types of markets, we need a dynamic oligopoly model, which is beyond the scope of this paper.
} 
lower dispersion in large markets may reflect the fact that higher demand substitutability implies more intense competition (Syverson, 2004).

\subsection{Exit}

A negative relationship between productivity and exit is one of the most robust findings in the productivity literature (Olley and Pakes, 1996; Bartelsman and Doms, 2000; Syverson, 2011). Table 5 shows the transitions between the productivity percentile bins and exit in local markets. A higher share of exit occurs from the lower half of the productivity distribution in large store entry markets than in non-entry markets. More than 25 percent of stores in the p10 bin exit in large store entry markets, but only 20 percent of such stores exit in non-entry markets. ${ }^{54}$

A store's dynamic optimization problem provides the policy function for exit, which states that a store's optimal decision to exit is a function of the state variables (Olley and Pakes, 1996). The probability of exit is thus a function of the store's state variables. We work under the assumption that shocks to demand $u_{j t}^{d}$ are i.i.d. and are not predictable by stores when exit decisions are made. ${ }^{55}$

Table 8 shows regression results from simple probit specifications for the probability to exit, with our estimates of productivity, the number of large store entrants, capital, and demand shifters as explanatory variables. The coefficient of large store entry has the expected positive sign and is

\footnotetext{
${ }^{54}$ In both market groups, approximately 3-4 percent of stores exit in p90. This result might be due to the re-structuring and re-organization of incumbent stores. Most importantly, there are no systematic differences in the exit of high-productivity stores in markets with or without large store entry. Although large store entrants represent "physical entry", the data only allow us to link estimated productivity and exit based on organization number. The proposed estimation approach accounts for these possible selection problems by controlling for survival probabilities when estimating store productivity (Olley and Pakes, 1996).

${ }^{55}$ If stores can observe or predict the demand shocks $u_{j t}^{d}$ after controlling for observable demand shifters, it is not possible to estimate the exit regression as below without including the demand shocks in the productivity process. Exit decisions include physical exit and the re-structuring/re-organization of stores, which cause changes in stores' organization numbers.
} 
significant at conventional significance levels in all of the specifications. The probability of exit is approximately 0.18 higher for stores after a large store enters a local market. In line with both theory and previous empirical studies (e.g., Olley and Pakes, 1996), exit is less likely if productivity and the capital stock are high.

The interaction term between large store entrants and a dummy variable for stores with productivity below the 25th percentile is positive and jointly statistically significant with large store entry. These results are robust to additional controls. Hence, the entry of large stores forces low-productivity stores to exit. Exit is also less likely in high income growth markets and markets with low population density.

\subsection{Summary and discussion of results}

The results shown in Tables 5-8 indicate that large store entrants increase store productivity, aggregate local market productivity, and exit. These findings show the mechanisms that have resulted in an observed trend toward larger but fewer stores in the retail industry. That the entry of large stores has the largest effect on incumbents with low productivity is an indirect effect of competition. Large store entrants induce exit and bring new demand but also capture demand from incumbent stores, where the net effect is higher competitive pressure on stores with low productivity. ${ }^{56}$ Overall, the results indicate that the entry of large stores both induces both productivity gains within stores and creates selection among stores with different levels of productivity (i.e., incumbent productivity increases, and low-productivity stores are forced to exit).

\footnotetext{
${ }^{56}$ The dynamic effect of competition is included in the measured effect of a new store entrant on productivity, and the positive effect on productivity should be balanced with the decrease in the number of stores, i.e., the lower product differentiation available to consumers. Maican and Orth (2013) use a dynamic entry-exit game with store type differentiation to study large store entry and industry dynamics in Swedish retail food from 2001 to 2008 in detail.
} 


\subsection{Robustness and specification tests}

This section discusses the main robustness and specification tests. The online appendix presents additional robustness results.

Alternative specifications. Table 9 shows robustness checks using alternative empirical specifications. First, we present robustness checks on our main specification (column (2) of Table 4), with the only difference that we do not control for endogeneity of large store entrants, aggregate quantity, or wages. The results are reported in column (3) of Table 9. The goal is to see how the results change when we treat these variables as exogenous. The positive marginal effects of large store entrants on store productivity remain robust when we do not control for endogeneity. The median increase in store productivity due to a large store entrant is 5 percent. However, the standard deviation of the marginal effect is slightly larger when we do not control for endogeneity. The sales-generating function estimates show a slightly smaller capital coefficient $\left(\beta_{k}=0.308\right)$ and a slightly larger labor coefficient $\left(\beta_{l}=0.966\right) .{ }^{57}$ The demand elasticity $(|\eta|)$ increases from 2.04 to 2.62 , and the scale increases from 1.16 to 1.27 . The modest impact of a large store entrant on residual demand and hence prices remains when not controlling for endogeneity. The coefficient of large store entrants $\left(\beta_{e}\right)$ is small and negative (-0.003) but not statistically significant. ${ }^{58}$

Second, not controlling for the effect of current large store entrants on prices in our main specification results in a 2 percentage-point lower median impact of large store entrants on store productivity (results not reported); this result is in line with the theoretical predictions presented in Section 5.1. Hence, part of the productivity increase caused by large store entrants is in fact an effect on prices, which is important to control for (De Loecker, 2011).

\footnotetext{
${ }^{57}$ When not controlling for the fact that large store entrants affect prices, we expect the coefficients for labor and capital to be biased because of the positive correlation between inputs and demand shocks, which are part of the productivity measure in this case. After controlling for local market competition, the capital coefficient increases, which is in the direction of controlling for selection bias (Olley and Pakes, 1996).

${ }^{58}$ This small effect might be due to the fact that, because of data constraints, our simple demand system only allows us to estimate average effects and does not consider distributional effects. Large store entrants may, e.g., reduce prices in nearby stores.
} 
Third, the fact that the impact of large store entrants on productivity is biased when not controlling for the impact on demand is confirmed by a robustness check presented in column (1) of Table 9. Considering a simple parametric specification that explains productivity by the number of large store entrants, $\omega_{j t}=\beta_{e} e_{m t}^{L}+u_{j t}^{e}$, where $u_{j t}^{e}$ are i.i.d., we can interpret $\beta_{e}$ as the effect on productivity when estimating the service-generating function, $y_{j t}=\beta_{0}+\beta_{l} l_{j t}+\beta_{k} k_{j t}+\beta_{e} e_{m t}^{L}+u_{j t}^{e}+v_{j t}$, by OLS. The results show that the coefficient for large store entrants is positive but small (0.009) and not statistically significant. In addition to the standard problems of production function estimation and the use of strong assumptions to identify $\beta_{e}$ (i.e., $\left.E\left[u_{j t}^{e}+v_{j t} \mid e_{m t}^{L}\right]=0\right)$, this specification does not address the effect of large store entrants on prices.

Fourth, the robustness specification in column 2 of Table 9 considers the role of omitting imperfect competition. This specification corresponds to the implementation of the OP method with labor demand as a proxy. A new large store decreases median productivity by approximately 2 percent. The negative impact of a large store entrant suggests that we must control for demand in local markets.

Parametric labor demand and test of static labor. An attractive alternative is to use a parametric labor demand function to recover productivity (Doraszelski and Jaumandreu, 2013). The functional form of the parametric labor demand function is shown in Section 5. Our identification strategy and empirical findings are robust to the choice of the labor demand function. The estimates are presented in column (4) of Table 9 (Section $\mathrm{E}$ in the online appendix shows additional results and discusses the empirical strategy using parametric labor demand).

In the parametric labor demand specification, we test the validity of our assumption that labor is static. If the inverse labor demand function is misspecified, the labor coefficient in the service-generating function differs from that in the inverse labor demand function. We estimate the restricted and unrestricted models and compute the GMM distance statistic, $D_{N}=N *\left[Q_{N}\left(\beta_{\text {restricted }}\right)-Q_{N}\left(\beta_{\text {unrestricted }}\right)\right]$, to test the null of equal labor coefficients. The null is not rejected, i.e., our assumption of static labor is 
valid.

Relaxing the timing assumption on labor. If there are hiring and firing costs of employees, labor is a static and fixed input. We can then use current labor $l_{j t}$ as an instrument in our main specification. The results are directly comparable with those when labor is static and variable, i.e., Tables 4 and 7. Under perfect competition, the coefficient for labor (adjusted with elasticity) increases from 0.406 to 0.647 , and the coefficient for capital increases from 0.188 to 0.240 . Controlling for imperfect competition, the labor coefficient increases to 0.491 , the capital coefficient increases to 0.412 , and demand elasticity is -2.88 (slightly larger than in Table 4 ). Using the moment condition based on current labor gives similar support of the marginal effect of large entrants (Table 7).

Alternative production technology. For our main specification, we relax the Cobb-Douglas technology in equation (1) and consider a translog production function $q_{j t}=\beta_{l} l_{j t}+\beta_{k} k_{j t}+\beta_{l l} l_{j t}^{2}+\beta_{k k} k_{j t}^{2}+\beta_{l k} l_{j t} k_{j t}+\omega_{j t}^{p}+u_{j t}^{p}$, which requires the estimation of three additional parameters: labor squared $\left(\beta_{l l}\right)$, capital squared $\left(\beta_{k k}\right)$, and the interaction between labor and capital $\left(\beta_{l k}\right)$. The results, which are not reported but are available from the authors upon request, are consistent with our previous findings. Large store entrants have a greater impact on low-productivity incumbents than on high-productivity incumbents. An additional large store entrant increases productivity by approximately 4 percent for a 10th percentile productivity store, by approximately 2 percent for a median store, and by approximately 0.1 percent for a 90 th percentile store.

Alternative moments. As suggested in Section 5, an alternative set of moments that can be used in the estimation of the sales-generating function $\boldsymbol{\beta}$ is $E\left[\xi_{j t} \mid l_{j t-1}, k_{j t-1}, p o l_{m t-1}, \sum_{o \neq m} e_{o t-1}^{L}, q_{m t-1}, \mathbf{x}_{j t-1}\right]=0$ (i.e., an overidentified specification). This set of moments can be used when the moment $E\left[\xi_{j t} \mid e_{m t}^{L}\right]=0$ does not hold. Using this overidentified specification, there is no significant change in the estimation of $\boldsymbol{\beta}$. The Sargan test cannot reject the null hypothesis of overidentified restrictions $(p$-value $=0.963)$, which suggests that the overidentifying instruments are valid. In addition, the median marginal effect of large entrants on productivity (3.6 percent) is 
close the findings presented in Section 6 (4 percent).

Decomposition. We also estimate the contribution of all store entrants to aggregate productivity growth during the period from 1997 to 2002 using various productivity decompositions (Griliches and Regev, 1995 and Foster et al., 2001). Incumbent stores that increase their productivity at the initial sales level contribute approximately 8 percent (within), and net entry contributes 2-4 percent (Section $\mathrm{F}$ in the online appendix). These findings suggest the importance of understanding the factors that drive productivity growth.

\section{Conclusions}

The present study provides new insights into competition and productivity differences among retail stores. Net entry is found to foster almost all labor productivity growth in the U.S. retail sector (Foster et al., 2006). However, total-factor productivity in retail markets has rarely been studied, in contrast with manufacturing. We present a first attempt to use recent advances in the semiparametric estimation of production functions to estimate productivity in retail markets and to investigate how the entry of large ("big-box") stores influences stores' efficiency shocks and demand shocks. On both sides of the Atlantic, the pros and cons of the big-box format have been widely debated (the "Walmart effect").

We provide a dynamic structural model to obtain accurate measures of total-factor productivity in retail food. The framework addresses a set of measurement issues in services, i.e., substitution of capital and labor, difficulties in measuring output, and the importance of modeling the external environment in local markets. We analyze whether large store entrants force low-productivity stores out of the market and increase productivity among the surviving stores with different positions in the productivity distribution. Our empirical application relies on detailed data on all retail food stores in Sweden, a sector that is representative of many OECD markets in terms of market structure and regulation. 
The results show substantial heterogeneity in the positive effects of large store entrants on future productivity. A large store entrant increases productivity in the median store by 3.1 percent. A key finding is that productivity increases decline toward the upper part of the productivity distribution. Productivity increases by 1-2 percentage points more for a store in the 25th local market productivity percentile than for a store in the 75 th percentile. Stores with low productivity are smaller, and large store entrants force them either to exit or to increase their productivity to survive. These stores increase their productivity relatively more than do stores with high productivity.

These results can be rationalized by the fact that increased competition from large store entry forces existing stores to improve their productivity and low-productivity stores to exit. Productivity improvements are larger in the bottom part of the local market productivity distribution, which decreases productivity dispersion. Our findings support previously discussed mechanisms of how competition affects productivity (Asplund and Nocke, 2006; Syverson, 2011). Furthermore, not controlling for the contemporaneous effect of large store entrants on prices leads to underestimation of their impact on store productivity. We conclude that the entry of big-box stores catalyzes retail productivity.

Our findings contribute knowledge that is relevant to competition policy, as entry regulation issues are a significant concern for policymakers in Europe, where such regulations are generally much more restrictive than in the U.S. As an example, the European Commission recently highlighted an investigation of the food sector (European Commission, 2012). We argue that a more restrictive design and application of entry regulations can hinder aggregate productivity growth in local markets. In addition to productivity, entry regulations compound a wide range of other aspects. How to balance potential productivity growth against increased traffic and broader environmental effects and the consideration of dynamic game frameworks are interesting topics for future research (Pakes et al., 2007; Holmes, 2011; Dunne et al., 2013; Maican and Orth, 2013; and Sweeting, 2013). 


\section{References}

Ackerberg, D., L. Benkard, S. Berry, and A. Pakes (2007):

"Econometric Tools for Analyzing Market Outcomes," Handbook of Econometrics, 6, 4171-4276.

Ackerberg, D., K. Caves, and G. Fraser (2015): "Identification Properties of Recent Production Function Estimators," Econometrica forthcoming.

Ackerberg, D., X. Chen, and J. Hahn (2012): "A Practical Asymptotic Variance Estimator for Two-Step Semiparametric Estimators," Review of Economics and Statistics, 94(2), 481-498.

Aghion, P., And R. Griffith (2005): Competition and Growth: Reconciling Theory and Evidence. MIT Press, MA.

Asplund, M., And R. Friberg (2002): "Food Prices and Market Structure in Sweden," Scandinavian Journal of Economics, 104(4), 547-567.

Asplund, M., And V. Nocke (2006): "Firm Turnover in Imperfectly Competitive Markets," Review of Economic Studies, 73(2), 295-327.

BAIRAM, E. (1994): Homogeneous and Nonhomeogeneous Production Functions. Avebury, Ashate Publishing Ltd.

Bartelsman, E., And M. Doms (2000): "Understanding Productivity: Lessons from Longitudinal Microdata," Journal of Economic Literature, 38(3), 569-594.

BAsker, E. (2005): "Job Creation or Destruction? Labor-Market Effects of Wal-Mart Expansion," Review of Economics and Statistics, 87(1), 174-183.

(2007): "The Causes and Consequences of Wal-Mart's Growth," Journal of Economic Perspectives, 21(3), 177-198.

(2012): "Raising the Barcode Scanner: Technology and Productivity in the Retail Sector," American Economic Journal: Applied Economics, 4(3), 1-27.

(2015): "Change at the Checkout: Tracing the Impact of a Process Innovation," Journal of Industrial Economics, 63(2), 339-370. 
Basker, E., S. KlimeK, and P. VAn (2012): "Supersize it: The Growth of Retail Chains and the Rise of the "Big-Box" Format," Journal of Economics and Management Strategy, 21(3), 541-582.

Basker, E., And M. Noel (2009): "The Evolving Food Chain: Competitive Effects of Wal-Mart's Entry into the Supermarket Industry," Journal of Economics and Management Strategy, 18(4), 177-198.

Bertrand, M., and F. Kramarz (2002): "Does Entry Regulation Hinder Job Creation? Evidence from the French retail industry," Quarterly Journal of Economics, 117(4), 1369-1413.

Bond, S., And M. Söderbom (2005): "Adjustment Costs and the Identification of Cobb-Douglas Production Functions," Working Paper 05/04, Institute of Fiscal Studies.

Boylaud, O., and G. Nicoletti (2001): "Regulatory reform in retail distribution," OECD Working Paper 32.

Buccirossi, P., L. Ciari, T. Duso, G. Spagnolo, and C. Vitale (2013): "Competition Policy and Productivity Growth: An Empirical Assessment," Review of Economics and Statistics, 95(4), 1324-1336.

Chamber Trade Sweden (2013): "Market Report Food: Focus on the Swedish Market," Technical Report, Stockholm.

Collard-Wexler, A. (2011): "Productivity Dispersion and Plant Selection in Ready-Mix Concrete Industry," Mimeo, New York University.

De Loecker, J. (2011): "Product Differentiation, Multi-Product Firms and Estimating the Impact of Trade Liberalization on Productivity," Econometrica, 79(5), 1407-1451.

Djankov, S., R. La Porta, F. Lopez-de Silanes, and A. Shleifer (2002): "The Regulation of Entry," Quarterly Journal of Economics, CXVII(1), 1-37.

Doraszelski, U., And J. Jaumandreu (2013): "R\&D and Productivity: Estimating Endogenous Productivity," Review of Economic Studies, 80(4), 1338-1383.

Dunne, T., S. Klimek, M. Roberts, and Y. Xu (2013): "Entry, Exit and the Determinants of Market Structure," The RAND Journal of Economics, 44(3), 462-487. 
Ellickson, P. (2015): "The Evolution of the Supermarket Industry: From A\&P to Wal-Mart," Handbook on the Economics of Retail and Distribution forthcoming.

Ellickson, P., And P. Grieco (2013): "Wal-Mart and the Geography of Grocery Retailing," Journal of Urban Economics, 75, 1-14.

Ericson, R., And A. Pakes (1995): "Markov-Perfect Industry Dynamics: A Framework for Empirical Work," Review of Economic Studies, 62(1), 53-83.

European Commission (2012): "The Economic Impact of Modern Retail on Choice and Innovation in the EU Food Sector," Written Declaration.

European Competition Network (2011): "ECN Brief Extended Issue," ECN Brief 05/2011, European Competition Network.

European Parliament (2008): "On Investigating and Remedying the Abuse of Power by Large Supermarkets Operating in the European Union," Written Declaration 0088, European Parliament.

Foster, L., J. Haltiwanger, and C. Krizan (2001): "The Link Between Aggregate and Micro Productivity Growth: Evidence from Retail Trade," NBER Working Paper 13783.

(2006): "Market Selection, Reallocation, and Restructuring in the U.S. Retail Trade Sector in the 1990s," Review of Economics and Statistics, 88(4), 748-758.

Foster, L., J. Haltiwanger, and C. Syverson (2008): "Reallocation, Firm Turnover, and Efficiency: Selection on Productivity or Profitability?," American Economic Review, 98(1), 394-425.

Gandhi, A., S. Navarro, and D. Rivers (2014): "On the Identification of Production Functions: How Heterogenous is Productivity?," mimeo, University of Wisconsin-Madison.

Greenstone, M., R. Hornbeck, and E. Moretti (2010): "Identifying Agglomeration Spillovers: Evidence from Winners and Losers of Large Plant Openings," Journal of Political Economy, 118(3), 536-598.

Griffith, R., And H. Harmgart (2005): "Retail Productivity," International Review of Retail, Distribution and Consumer Services, 15(3), 281-290. 
Griliches, Z., And H. Regev (1995): "Productivity and Firm Turnover in Israeli Industry: 1979-1988," Journal of Econometrics, 65, 175-203.

Hall, R. (1988): "The Relation between Price and Marginal Cost in U.S. Industry," Journal of Political Economy, 96(5), 921-947.

Haltiwanger, J., R. Jarmin, and C. Krizan (2010): "Mom-andPop meet Big-Box: Complements or substitutes?," Journal of Urban Economics, 67, 116-134.

Hausman, J. (1997): The Economics of New Goodschap. Valuation of New Goods Under Perfect and Imperfect Competition, pp. 207-248. University of Chicago Press.

Holmes, T. (2011): "The Diffusion of Wal-Mart and Economies of Density," Econometrica, 79(1), 253-302.

JiA, P. (2008): "What Happens When Wal-Mart Comes to Town: An Empirical Analysis of the Discount Retailing Industry," Econometrica, 76(6), 1263-1316.

Klette, T., and Z. Griliches (1996): "The Inconsistency of Common Scale Estimators when Output Prices are Unobserved and Endogenous," Journal of Applied Econometrics, 11(4), 343-361.

Leibenstein, H. (1966): "Allocative Efficiency vs. "X-Efficiency"," The American Economic Review, 56(3), 392-415.

Levinsohn, J., And A. Petrin (2003): "Estimating Production Functions Using Inputs to Control for Unobservables," Review of Economic Studies, 70(2), 317-341.

MacDonald, J. (1994): "Does Import Competition Force Efficient Production?," Review of Economics and Statistics, 76(4), 721-727.

Maican, F., And M. Orth (2013): "Entry Regulations, Product Differentiation and Determinants of Market Structure," Mimeo, Reserach Institute of Industrial Economics (IFN) and University of Gothenburg.

(2015): "A Dynamic Analysis of Entry Regulations and Productivity in Retail Trade," International Journal of Industrial Organization, 40, 67-80.

MatsA, D. (2011): "Competition and Product Quality in the Supermarket Industry," Quarterly Journal of Economics, 126, 1539-1591. 
Nickell, S. (1996): "Competition and Corporate Performance," Journal of Political Economy, 104(4), 724-746.

Ofer, G. (1973): "Returns to Scale in Retail Trade," Review of Income and Wealth, 19(4), 363-384.

Olley, S., And A. Pakes (1996): "The Dynamics of Productivity in the Telecommunications Equipment Industry," Econometrica, 64(6), 12631297.

Pakes, A. (1991): "Dynamic Structural Models: Problems and Prospects. Mixed Continuous Discrete Controls and Market Interactions," Cowles Foundation Discussion Paper No. 984.

Pakes, A., S. Berry, and M. Ostrovsky (2007): "Simple Estimators for the Parameters of Dyscrete Dynamic Games, with Entry/Exit Examples," RAND Journal of Economics, 38(2), 373-399.

PILAT, D. (1997): "Regulation and Performance in the Distribution Sector," OECD Working Papers 180.

Roeger, W. (1995): "Can Imperfect Competition Explain the Difference between Primal and Dual Productivity Measures? Estimates for U.S. Manufacturing," Journal of Political Economy, 103(2), 316-330.

Schivardi, F., And E. Viviano (2011): "Entry Barriers in Retail Trade," Economic Journal, 121(155), 145-170.

Staiger, D., and J. Stock (1997): "Instrumental Variables Regression with Weak Instruments," Econometrica, 65(3), 557-586.

Swedish Competition Authority (2001:4): "Kan Kommunerna Pressa Matpriserna? (Can the Municipalities Put Pressure on Prices?)," Technical Report 4, Stockholm.

_ (2002:6): "Dagligvaruhandeln: Struktur, Ägarform och relation till leverantörer? (Retail Food: Market structure, ownership and suppliers)," Technical Report 6, Stockholm.

Swedish Trade Federation (2011): "Svenskarnas Resvanor: SåReser Vi När Vi Handlar," Technical Report, Stockholm.

Sweeting, A. (2010): "The effects of mergers on product positioning: evidence from the music radio industry," RAND Journal of Economics, $41(2), 372-397$. 
(2013): "Dynamic Product Positioning in Differentiated Product Markets: The Effect of Fees for Musical Performance Rights on the Commercial Radio Industry," Econometrica, 81(5), 1763-1803.

Syverson, C. (2004): "Market Structure and Productivity: A Concrete Example," Journal of Political Economy, 112(2), 1181-1222.

(2011): "What Determines Productivity?," Journal of Economic Literature, 49(2), 326-365.

Wooldridge, J. M. (2009): "On Estimating Firm-Level Production Functions Using Proxy Variables to Control for Unobservables," Economics Letters, 104(3), 112-114. 
Table 1: Characteristics of the Swedish Retail Food Market

\begin{tabular}{|c|c|c|c|c|c|c|}
\hline \multicolumn{7}{|c|}{ A. FS-RAMS } \\
\hline Year & $\begin{array}{l}\text { No. of } \\
\text { stores }\end{array}$ & $\begin{array}{c}\text { No. of } \\
\text { employees }\end{array}$ & $\begin{array}{l}\text { Wage } \\
\text { bill }\end{array}$ & $\begin{array}{l}\text { Value } \\
\text { added }\end{array}$ & $\begin{array}{l}\text { Total } \\
\text { sales }\end{array}$ & $\begin{array}{l}\text { Value added } \\
\text { per employee }\end{array}$ \\
\hline 1996 & 3,714 & 74,100 & $9,882,234$ & $18,319,407$ & $141,743,876$ & 247.22 \\
\hline 1997 & 3,592 & 73,636 & $10,322,136$ & $18,838,130$ & $142,840,611$ & 255.83 \\
\hline 1998 & 3,482 & 74,696 & $10,766,043$ & $19,185,120$ & $147,726,647$ & 256.84 \\
\hline 1999 & 3,398 & 74,758 & $11,110,785$ & $19,570,472$ & $152,160,949$ & 261.78 \\
\hline 2000 & 3,287 & 77,180 & $11,536,063$ & $20,389,492$ & $154,106,865$ & 264.18 \\
\hline 2001 & 3,094 & 76,905 & $11,522,482$ & $20,748,902$ & $158,512,132$ & 269.79 \\
\hline 2002 & 3,067 & 80,931 & $12,081,931$ & $22,473,696$ & $179,335,162$ & 277.69 \\
\hline \multicolumn{7}{|c|}{ B. DELFI } \\
\hline Year & $\begin{array}{l}\text { Large } \\
\text { stores }\end{array}$ & $\begin{array}{l}\text { Large } \\
\text { entry }\end{array}$ & $\begin{array}{c}\text { Mean } \\
\text { sales space } \\
m^{2}\left(f t^{2}\right)\end{array}$ & $\begin{array}{c}\text { Total } \\
\text { space space } \\
m^{2}\left(f t^{2}\right)\end{array}$ & $\begin{array}{l}\text { Total } \\
\text { sales }\end{array}$ & $\begin{array}{c}\text { Value added per } \\
\text { sales space } \\
m^{2}\left(f t^{2}\right)\end{array}$ \\
\hline 1996 & 905 & 21 & $538(5,792)$ & $2,510,028(27,017,711)$ & $129,326,000$ & $7.29(0.67)$ \\
\hline 1997 & 925 & 8 & $550(5,916)$ & $2,483,248(26,729,464)$ & $126,732,397$ & $7.58(0.70)$ \\
\hline 1998 & 926 & 9 & $587(6,315)$ & $2,552,794(27,478,041)$ & $130,109,604$ & $7.52(0.69)$ \\
\hline 1999 & 936 & 18 & $604(6,500)$ & $2,534,082(27,276,632)$ & $133,156,023$ & $7.72(0.71)$ \\
\hline 2000 & 948 & 23 & $654(7,040)$ & $2,612,566(28,121,432)$ & $138,314,044$ & $7.80(0.72)$ \\
\hline 2001 & 942 & 28 & $689(7,419)$ & $2,520,110(27,126,244)$ & $139,352,920$ & $8.23(0.76)$ \\
\hline 2002 & 932 & 5 & $718(7,733)$ & $2,575,784(27,725,503)$ & $142,532,944$ & $8.72(0.81)$ \\
\hline
\end{tabular}

NOTE: FS-RAMS is provided by Statistics Sweden and consists of all organization numbers in SNI code 52.1, i.e., "multi-store" units that contain one store or several (e.g., due to the same owner). Sales (incl. $12 \%$ VAT), value-added, wages, value-added per employee and sales space are measured in thousands of 1996 SEK $(1 \mathrm{USD}=6.71 \mathrm{SEK}, 1 \mathrm{EUR}=8.63 \mathrm{SEK})$. DELFI is provided by Delfi Marknadspartner AB. Sales in DELFI are collected by surveys and reported in classes, while sales are based on tax reporting in FS-RAMS. Therefore, total sales are lower in DELFI than in FS-RAMS. Value-added per employee is defined using the number of full-time adjusted employees in FS-RAMS. Value-added per square meter of sales space $\left(m^{2}\right)$ and value-added per square feet of sales space $\left(f t^{2}\right)$ are defined using value-added from FS-RAMS and sales space from DELFI. From 1996 to 2002, the total population in Sweden increased from 8,844,499 to 8,940,788. 
Table 2: Distribution of stores and firms across local markets and years

\begin{tabular}{|c|c|c|c|c|c|c|c|c|}
\hline & \multicolumn{5}{|c|}{ No. of stores } & \multirow{2}{*}{$\begin{array}{l}\text { Total } \\
\text { no. of } \\
\text { stores }\end{array}$} & \multirow{2}{*}{$\begin{array}{l}\text { No. of } \\
\text { firms }\end{array}$} & \multirow{2}{*}{$\begin{array}{l}\text { Share of pop } \\
\text { with nearest } \\
\text { store }<2 \mathrm{~km}\end{array}$} \\
\hline & ICA & Axfood & Coop & Bergendahls & Others & & & \\
\hline Minimum & 0 & 0 & 0 & 0 & 0 & 3 & 1 & 0.45 \\
\hline 25 th percentile & 3 & 1 & 1 & 0 & 3 & 9 & 3 & 0.66 \\
\hline 50th percentile & 5 & 2 & 2 & 0 & 5 & 15 & 3 & 0.75 \\
\hline 75th percentile & 9 & 4 & 5 & 0 & 8 & 25 & 3 & 0.82 \\
\hline Maximum & 86 & 93 & 88 & 12 & 218 & 460 & 4 & 1.00 \\
\hline Mean & 7.25 & 3.66 & 3.91 & 0.22 & 8.25 & 23.29 & 2.86 & 0.74 \\
\hline Std. deviation & 7.74 & 6.76 & 5.81 & 0.89 & 16.87 & 35.34 & 0.55 & 0.12 \\
\hline
\end{tabular}

NOTE: This table shows the distribution of the number of stores and firms across local markets as well as the share of population with less than 2 kilometers to the nearest store. ICA, Axfood, Coop and Bergendahls are defined as firms. Municipalities, considered as local markets, increase from 288 to 290 due to three municipality break-ups during the period, which gives a total of 2,021 market-year observations. Distance to the nearest store is calculated based on $800 \times 800$ meter grids and is only available for 2002 (290 observations). 
Table 3: Local market characteristics

\begin{tabular}{|c|c|c|c|c|c|c|}
\hline Year & 1997 & 1998 & 1999 & 2000 & 2001 & 2002 \\
\hline \multicolumn{7}{|c|}{ A. Productivity measures for all markets: mean (std. dev.) } \\
\hline Value-added per employee & $\begin{array}{c}249.33 \\
(70.04)\end{array}$ & $\begin{array}{l}252.11 \\
(49.95)\end{array}$ & $\begin{array}{c}271.66 \\
(149.64)\end{array}$ & $\begin{array}{l}256.93 \\
(54.98)\end{array}$ & $\begin{array}{c}258.93 \\
(64.79)\end{array}$ & $\begin{array}{l}266.28 \\
(57.62)\end{array}$ \\
\hline Value-added per square meter $\left(\mathrm{m}^{2}\right)$ & $\begin{array}{c}4.85 \\
(4.77)\end{array}$ & $\begin{array}{c}5.01 \\
(5.16)\end{array}$ & $\begin{array}{c}5.11 \\
(5.29)\end{array}$ & $\begin{array}{c}4.95 \\
(5.72)\end{array}$ & $\begin{array}{c}5.16 \\
(5.71)\end{array}$ & $\begin{array}{c}5.55 \\
(5.97)\end{array}$ \\
\hline Value-added per square feet $\left(f t^{2}\right)$ & $\begin{array}{c}0.43 \\
(0.38)\end{array}$ & $\begin{array}{c}0.45 \\
(0.43)\end{array}$ & $\begin{array}{c}0.46 \\
(0.45)\end{array}$ & $\begin{array}{c}0.44 \\
(0.46)\end{array}$ & $\begin{array}{c}0.46 \\
(0.46)\end{array}$ & $\begin{array}{c}0.49 \\
(0.49)\end{array}$ \\
\hline Total no. of markets & 285 & 285 & 286 & 286 & 286 & 287 \\
\hline \multicolumn{7}{|l|}{ B. Markets with large entrants: median } \\
\hline No. of stores & 35 & 45 & 28 & 30 & 33 & 20 \\
\hline No. of all entrants & 2 & 2 & 2 & 2 & 1 & 1 \\
\hline No. of all exits & 2 & 2 & 2 & 3 & 1 & - \\
\hline Population & 43,646 & 54,933 & 37,054 & 40,363 & 58,266 & 13,150 \\
\hline Population density & 69.30 & 48.70 & 66.92 & 78.65 & 69.30 & 31.80 \\
\hline Per capita income & 149.20 & 157.70 & 161.40 & 170.70 & 179.10 & 177.80 \\
\hline Total no. of markets & 8 & 8 & 19 & 19 & 21 & 5 \\
\hline \multicolumn{7}{|c|}{ C. Markets without large entrants: median } \\
\hline No. of stores & 15 & 15 & 15 & 14 & 13 & 14 \\
\hline No. of all entrants & 0 & 0 & 1 & 0 & 0 & 0 \\
\hline No. of all exits & 0 & 1 & 1 & 1 & 0 & \\
\hline Population & 14,825 & 14,709 & 14,244 & 14,090 & 14,047 & 15,049 \\
\hline Population density & 25.80 & 25.76 & 25.10 & 24.99 & 24.66 & 25.90 \\
\hline Per capita income & 143.20 & 149.10 & 155.90 & 162.50 & 168.40 & 175.90 \\
\hline Total no. of markets & 277 & 277 & 267 & 267 & 265 & 282 \\
\hline \multicolumn{7}{|c|}{$\begin{array}{l}\text { NOTE: } 1996 \text { is left out because entrants are not observed. Municipalities are considered as local } \\
\text { markets. The three largest municipalities are excluded (Stockholm, Göteborg, Malmö). Municipali- } \\
\text { ties increase from } 285 \text { to } 287 \text { due to three municipality break-ups during the period. Value-added per } \\
\text { employee is defined using the number of full-time adjusted employees in FS-RAMS. Value-added per } \\
\text { employee and sales space are in thousands of } 1996 \text { SEK (1USD=6.71SEK, 1EUR=8.63 SEK). Sales } \\
\text { space, stores, entrants and exits come from DELFI. Population density is defined as total population } \\
\text { per square kilometer in the municipality. }\end{array}$} \\
\hline
\end{tabular}


Table 4: Service generating function estimates

\begin{tabular}{|c|c|c|c|}
\hline \multirow{3}{*}{ Log no. of labor } & \multirow{2}{*}{$\begin{array}{l}\text { OLS } \\
(1)\end{array}$} & \multicolumn{2}{|c|}{ Two-step estimation } \\
\hline & & $(2)$ & $(3)$ \\
\hline & $\begin{array}{l}0.735 \\
(0.004)\end{array}$ & $\begin{array}{c}0.406 \\
(0.008)\end{array}$ & $\begin{array}{c}0.797 \\
(0.012)\end{array}$ \\
\hline Log of capital & $\begin{array}{c}0.194 \\
(0.003)\end{array}$ & $\begin{array}{c}0.188 \\
(0.007)\end{array}$ & $\begin{array}{c}0.368 \\
(0.019)\end{array}$ \\
\hline Number of large store entrants & & $\begin{array}{l}-0.001 \\
(0.001)\end{array}$ & $\begin{array}{l}-0.002 \\
(0.002)\end{array}$ \\
\hline Population growth & & $\begin{array}{c}0.534 \\
(0.956)\end{array}$ & $\begin{array}{l}1.090 \\
(0.992)\end{array}$ \\
\hline Log of population density & & $\begin{array}{l}-0.016 \\
(0.007)\end{array}$ & $\begin{array}{l}-0.033 \\
(0.013)\end{array}$ \\
\hline Income growth & & $\begin{array}{c}0.567 \\
(0.128)\end{array}$ & $\begin{array}{l}1.158 \\
(0.195)\end{array}$ \\
\hline Market output $\left(-\frac{1}{\eta}\right)$ & & $\begin{array}{c}0.499 \\
(0.010)\end{array}$ & \\
\hline $\begin{array}{l}\text { Scale }\left(\beta_{l}+\beta_{k}\right) \\
\text { Demand elasticity }(\eta)\end{array}$ & 0.929 & $\begin{array}{r}1.165 \\
-2.042\end{array}$ & \\
\hline $\operatorname{Markup}\left(\frac{\eta}{1+\eta}\right)$ & & 1.95 & \\
\hline Sargan test (p-value) & & 0.985 & \\
\hline Test for ortogonality and weak intru & ents in & ep of OP f & work \\
\hline Sargan test (p-value) & & 0.094 & \\
\hline $\begin{array}{l}\text { Partial-F test: Large entrants } \\
\text { (p-value) }\end{array}$ & & $\begin{array}{l}65.665 \\
(0.000)\end{array}$ & \\
\hline $\begin{array}{l}\text { Partial-F test: Agggregate quantity } \\
\text { (p-value) }\end{array}$ & & $\begin{array}{r}236.053 \\
(0.000)\end{array}$ & \\
\hline $\begin{array}{l}\text { Partial-F test: Wages } \\
\text { (p-value) }\end{array}$ & & $\begin{array}{l}85.930 \\
(0.000)\end{array}$ & \\
\hline No. of obs. & 15,318 & 11,079 & \\
\hline
\end{tabular}

NOTE: The dependent variable is the log of deflated value-added. Labor is measured as the number of full-time adjusted employees. All regressions include year dummies. $O L S$ refers to ordinary least squares regression. OP refers to the Olley and Pakes (1996) estimation method. The specification in column (2) is a two-step estimation method that uses a nonparametric labor demand function and controls for imperfect competition and the endogeneity of large store entrants, aggregated local market quantity and wages in the first step of the OP framework (see Section 5). In specification (2), the reported parameters include elasticity, specifically, $\left(1+\frac{1}{\eta}\right) \beta_{l}$ for labor, $\left(1+\frac{1}{\eta}\right) \beta_{k}$ for capital, $-\frac{1}{\eta} \beta_{x}$ for exogenous demand shifters, and $-\frac{1}{\eta} \beta_{e}$ for large store entry (equation (3)). Column (3) shows the estimated coefficients for specification (2) without elasticity (structural parameters). Market output is measured as the market share weighted output in the municipality. Markup is defined as price over marginal cost. Reported standard errors (in parentheses) are computed using Ackerberg et al. (2012). The largest cities Stockholm, Gothenburg, and Malmo are excluded. 
Table 5: Transition matrix from t-1 (column) to t (row) in percentage

\begin{tabular}{|c|c|c|c|c|c|c|}
\hline Percentile & $<\mathrm{p} 10$ & p10-p25 & p25-p50 & p50-p75 & p75-p90 & $>$ p90 \\
\hline \multicolumn{7}{|c|}{ Markets with large store entrants in t-1 } \\
\hline$<\mathrm{p} 10$ & 24.24 & 21.05 & 11.43 & 2.78 & 2.44 & 1.49 \\
\hline p10-p25 & 33.33 & 31.58 & 14.86 & 8.33 & 1.22 & 4.48 \\
\hline p25-p50 & 13.64 & 23.16 & 38.29 & 19.44 & 12.2 & 11.94 \\
\hline p50-p75 & 1.52 & 6.32 & 19.43 & 35.56 & 29.27 & 10.45 \\
\hline p75-p90 & 1.52 & 0.00 & 3.43 & 23.33 & 32.93 & 29.85 \\
\hline$>$ p90 & 0.00 & 0.00 & 1.71 & 3.89 & 17.07 & 38.81 \\
\hline Exit & 25.76 & 17.89 & 10.86 & 6.67 & 4.88 & 2.99 \\
\hline \multicolumn{7}{|c|}{ Markets without large store entrants in t-1 } \\
\hline$<\mathrm{p} 10$ & 34.68 & 22.41 & 6.81 & 2.45 & 1.13 & 1.41 \\
\hline p10-p25 & 23.47 & 28.48 & 19.23 & 5.58 & 1.99 & 1.29 \\
\hline p25-p50 & 14.68 & 25.86 & 37.16 & 25.76 & 8.32 & 5.16 \\
\hline p50-p75 & 4.74 & 8.17 & 20.17 & 38.22 & 29.46 & 14.55 \\
\hline p75-p90 & 1.16 & 1.6 & 4.32 & 14.65 & 32.24 & 32.39 \\
\hline$>$ p90 & 0.69 & 1.26 & 1.99 & 5.06 & 19.58 & 40.96 \\
\hline Exit & 20.58 & 12.22 & 10.33 & 8.29 & 7.28 & 4.23 \\
\hline
\end{tabular}

NOTE: Productivity is estimated using our preferred specification of the model described in Section 3. Productivity is backed out from the labor demand function. Municipalities are considered as local markets. Large store entrants in period t- 1 are defined as the five largest store types in the DELFI data (hypermarkets, department stores, large supermarkets, large grocery stores, and other stores).

The largest cities Stockholm, Gothenburg, and Malmo are excluded. 
Table 6: Estimation of productivity process

\begin{tabular}{|c|c|c|}
\hline \multicolumn{3}{|c|}{$\begin{array}{l}\text { Panel A: Estimation of Markov productivity process using 3rd } \\
\text { order polynomial expansion in } \omega_{j t-1} \text { and } e_{m t-1}^{L}\end{array}$} \\
\hline & $F$-test & p-value \\
\hline$H_{0}:$ Coefficients of $\omega_{j t-1}$ terms are zero & 7.973 & 0.000 \\
\hline$H_{0}$ : Coefficients of $e_{m t-1}^{L}$ terms are zero & 3632.800 & 0.000 \\
\hline Adjusted $R^{2}$ & \multicolumn{2}{|c|}{0.986} \\
\hline No. of obs. & \multicolumn{2}{|c|}{11,079} \\
\hline \multicolumn{3}{|c|}{$\begin{array}{l}\text { Panel B: Distribution of the marginal effect at store level across } \\
\text { entry markets }\end{array}$} \\
\hline 25 th percentile & \multicolumn{2}{|l|}{0.013} \\
\hline 50 th percentile & \multicolumn{2}{|l|}{0.031} \\
\hline 75th percentile & \multicolumn{2}{|l|}{0.040} \\
\hline Mean & \multicolumn{2}{|l|}{0.022} \\
\hline
\end{tabular}

NOTE: Productivity is recovered from the labor demand function using the semiparametric two-step approach controls for simultaneity, selection, and imperfect competition (see Sections 3 and $5)$. We control for endogeneity of large entrants, market output and wages in the first stage. Large entrants in period $t-1$ are defined as the five largest store types in the DELFI data (hypermarkets, department stores, large supermarkets, large grocery stores, and other stores). Panel $B$ shows the distribution of the marginal effect across stores and years. For each store and year, the marginal effects arecomputed using store estimated productivity. The largest cities Stockholm, Gothenburg, and Malmo are excluded. 
Table 7: The impact of large store entrants on incumbents' productivity in local markets

\begin{tabular}{|c|c|c|}
\hline \multicolumn{3}{|c|}{ Panel A: Marginal effects by productivity percentiles in local markets } \\
\hline & Median & Std.Dev. \\
\hline 10th percentile productivity & 0.041 & 0.061 \\
\hline 25 th percentile productivity & 0.041 & 0.067 \\
\hline 50th percentile productivity & 0.040 & 0.076 \\
\hline 75th percentile productivity & 0.030 & 0.085 \\
\hline 90th percentile productivity & 0.022 & 0.094 \\
\hline
\end{tabular}

\begin{tabular}{lc}
\hline \hline \multicolumn{2}{l}{ Panel B: Change in aggregate local market productivity } \\
\hline & \\
Minimum & -0.010 \\
25th percentile & 0.003 \\
50th percentile & 0.015 \\
75th percentile & 0.023 \\
Maximum & 0.034 \\
& \\
Mean & 0.013 \\
\hline \hline
\end{tabular}

NOTE: The figures are computed using the estimated controlled Markov process of productivity. Panel $A$ shows the medians and standard deviations of the marginal effects across local entry markets and years. For each market and year, we computed the effects for various local productivity percentiles. Panel $B$ shows the distribution of changes in aggregate local market productivity after large store entry. The figures are computed as weighted averages of the productivity of individual stores, using market shares as weights, i.e., $\left.\sum_{j=1}^{n_{m}} s_{j t}\left(\partial h(\cdot) / \partial e_{m t-1}^{L}\right)\right)$. Productivity is recovered from the labor demand function using semiparametric two-step approach controls for simultaneity, selection, and imperfect competition (see Sections 3 and 5). We control for endogeneity of large store entrants, market output and wages in the first stage. We drop extreme values by removing 3 percent of the observations from each tail of the marginal effect distribution. Large entrants in period $t-1$ are defined as the five largest store types in the DELFI data (hypermarkets, department stores, large supermarkets, large grocery stores, and other stores). The largest cities Stockholm, Gothenburg, and Malmo are excluded. 
Table 8: Regression results: Exit

\begin{tabular}{|c|c|c|c|c|c|}
\hline & $(1)$ & $\overline{(2)}$ & $\overline{(3)}$ & $(4)$ & $(5)$ \\
\hline Log of productivity & $\begin{array}{l}-0.217 \\
(0.033)\end{array}$ & & & $\begin{array}{l}-0.179 \\
(0.037)\end{array}$ & \\
\hline Productivity in p25 & & $\begin{array}{c}0.102 \\
(0.038)\end{array}$ & & & \\
\hline No. of large entrants $(e L)$ & $\begin{array}{c}0.107 \\
(0.047)\end{array}$ & & $\begin{array}{c}0.006 \\
(0.067)\end{array}$ & $\begin{array}{c}0.081 \\
(0.048)\end{array}$ & $\begin{array}{c}0.004 \\
(0.068)\end{array}$ \\
\hline No. of large entrants $\times$ Productivity in $\mathrm{p} 25$ (inter) & & & $\begin{array}{c}0.181 \\
(0.090)\end{array}$ & & $\begin{array}{c}0.169 \\
(0.091)\end{array}$ \\
\hline Log of capital & & & & $\begin{array}{l}-0.044 \\
(0.017)\end{array}$ & $\begin{array}{l}-0.076 \\
(0.015)\end{array}$ \\
\hline Income growth & & & & $\begin{array}{l}-8.237 \\
(2.382)\end{array}$ & $\begin{array}{l}-8.499 \\
(2.379)\end{array}$ \\
\hline Population growth & & & & $\begin{array}{l}-3.266 \\
(2.600)\end{array}$ & $\begin{array}{l}-2.269 \\
(2.723)\end{array}$ \\
\hline Population density & & & & $\begin{array}{c}0.050 \\
(0.017)\end{array}$ & $\begin{array}{c}0.050 \\
(0.017)\end{array}$ \\
\hline$H_{0}:$ Sum of the coef. of $e L$ and inter $=0$ & & & $(0.003)$ & & $(0.006)$ \\
\hline Year fixed-effect & Yes & Yes & Yes & Yes & Yes \\
\hline No. of obs. & 7,486 & 7,486 & 7,486 & 7,486 & 7,486 \\
\hline
\end{tabular}

NOTE: This table shows probit regressions on exit. Productivity is estimated usingthe model described in Section 3. Reported standard errors are in parentheses. Large entrants are defined as the five largest store types in the DELFI data (hypermarkets, department stores, large supermarkets, large grocery stores, and other stores). The p-values are reported for the null hypothesis of the zero sum of the coefficients of the number of large store entrants and the interaction variable. The largest cities Stockholm, Gothenburg, and Malmo are excluded. 
Table 9: Robustness on service-generating function estimates

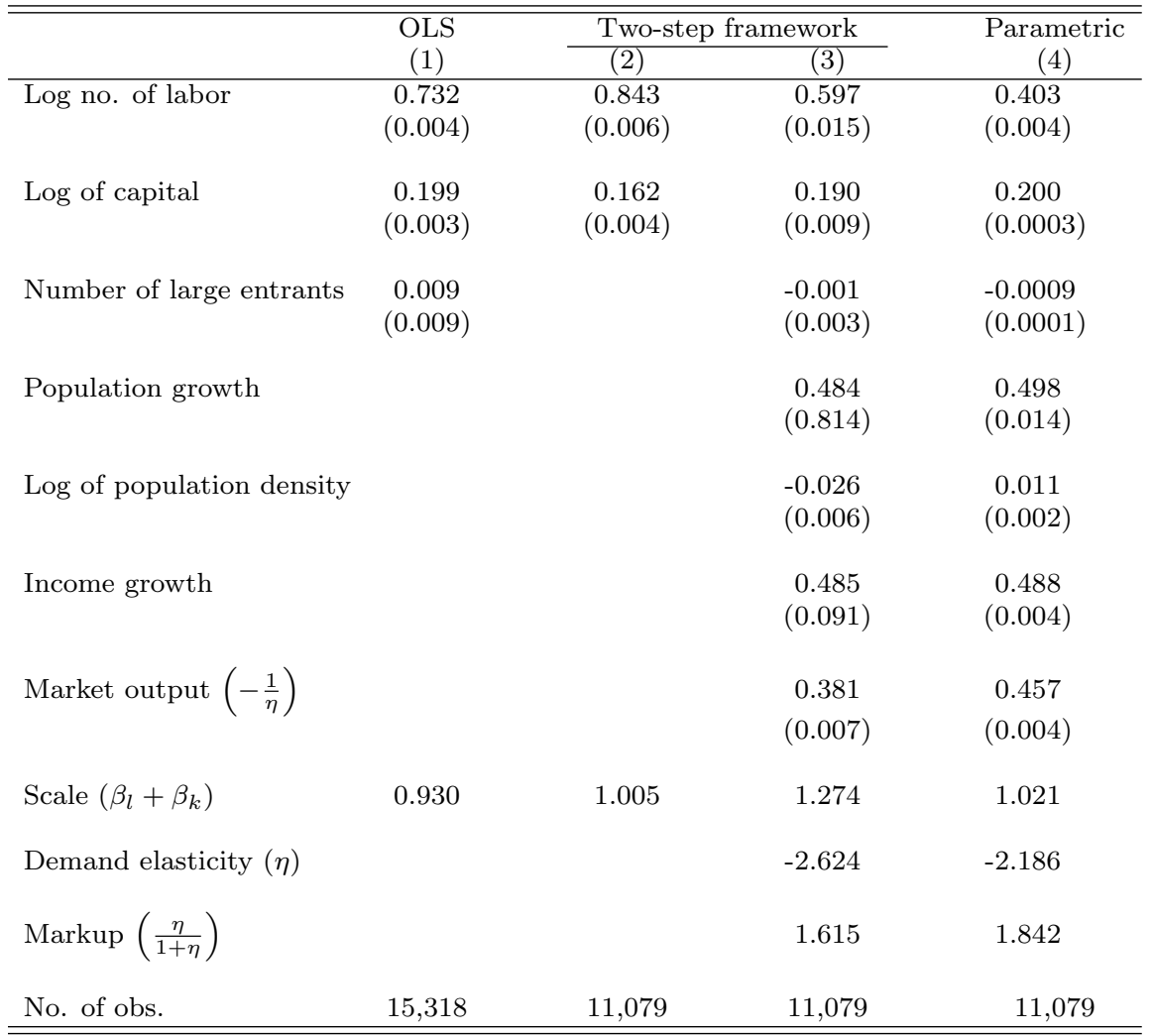

NOTE: The dependent variable is the log of deflated value added. OLS refers to ordinary least squares regression. Standard errors are in parentheses. The reported parameters in specifications (3) and (4) include elasticity, i.e., $\left(1+\frac{1}{\eta}\right) \beta_{l}$ for labor, $\left(1+\frac{1}{\eta}\right) \beta_{k}$ for capital, $-\frac{1}{\eta} \beta_{x}$ for exogenous demand shifters, and $-\frac{1}{\eta} \beta_{e}$ for large store entry (equation (5)). Labor is measured as the number of full-time adjusted employees. All regressions include year dummies. Specifications (2) and (3), which are based on the two-step estimation framework, include previous large store entrants and use the nonparametric labor demand function as a proxy for productivity; Specification (3) controls for imperfect competition but assumes that large entrants, aggregate local market quantity and wages are exogenous; Specification (4) is a one-step estimation using a parametric labor demand function and controlling for imperfect competition and endogeneity of large store entrants, aggregate local market quantity and wages (Doraszelski and Jaumandreu, 2013). Market output is measured as the market share weighted output in the municipality. Markup is defined as price over marginal cost. The largest cities Stockholm, Gothenburg, and Malmo are excluded. 


\title{
ONLINE APPENDIX \\ Productivity Dynamics and the Role of "Big-Box" Entrants in Retailing
}

\author{
Florin Maican* and Matilda Orth ${ }^{\dagger}$ \\ August 31, 2015
}

The online appendix contains six parts. Section A provides additional information about the data sets. Section B provides a more detailed discussion of the identification of the impact of large entrants on productivity and demand shocks presented in Section 3 in the paper. Section C provides a detailed discussion of wage variations in the data. Section D shows additional details about the estimation of the productivity process. Section $\mathrm{E}$ discusses the identification and estimation of the model presented in Section 3, using a parametric approach. Section F presents productivity decompositions at the industry level.

\section{Section A: PBA and data sources}

Entry regulation (PBA). On July 1, 1987, a new regulation was imposed in Sweden, the Plan and Building Act (PBA). Compared to the previous legislation, the decision process was decentralized, giving local governments power over entry in their municipality and citizens a right to appeal the decisions. Since 1987, only minor changes have been implemented in PBA. From April 1, 1992 to December 31, 1996, the regulation was slightly different, making explicit that the use of buildings should not

${ }^{*}$ Research Institute of Industrial Economics (IFN) and University of Gothenburg, Box 640, SE-405 30, Göteborg, Sweden, Phone +46-31-786 4866, Fax +46-31-786 4154, E-mail: florin.maican@economics.gu.se

${ }^{\dagger}$ Research Institute of Industrial Economics (IFN), Box 55665, SE-102 15, Stockholm, Sweden, Phone +46-8-665 4531, Fax +46-8-665 4599, E-mail: matilda.orth@ifn.se 
counteract efficient competition. Since 1997, PBA has been more or less the same as prior to 1992. Long time lags in the planning process make it impossible to directly evaluate the impact of decisions. In practice, differences because of the policy change seem small (Swedish Competition Authority 2001:4). Nevertheless, PBA is claimed to be one of the major entry barriers, resulting in different outcomes, e.g., price levels, across municipalities (Swedish Competition Authority 2001:4, Swedish Competition Authority 2004:2). Municipalities might then be able to put pressure on prices through the regulation. Those that constrain entry have less sales per capita, while those where large and discount stores have a higher market share also have lower prices.

Data. The data consist of two micro-data sets, DELFI and FS-RAMS. Both contain yearly information on all retail food stores in Sweden from 1996 to 2002. DELFI defines a unit of observation as a store based on its geographical location, i.e., its physical address. The data include store type, chain, revenue class, and sales space (in square meters). The store type classification (12 different) depends on size, location, product assortment, etc. A store is assumed to enter if it is observed in the data in year $t$ but not $t-1$, and a store is assumed to exit if it is observed in year $t$ but not $t+1$. In DELFI, entry and exit are defined only with respect to the geographical location of the store, so that an entrant introduces a new store to the market. In light of regulations and based on investigation of the impact of large of entrants on the productivity of incumbent stores, we believe that physical entry is the most relevant consideration. If a store changes owner or store type, it is not considered an entrant or exit. An advantage of DELFI is that it contains all stores and their physical locations; the disadvantages are a lack of input/output measures and the fact that revenues are reported in classes. DELFI is only used to define large entrants and to compute simple aggregate productivity measures.

The most disaggregated level for which more accurate input and output measures exist is organization number (Statistics Sweden, SCB). ${ }^{1}$ An

\footnotetext{
${ }^{1} \mathrm{~A}$ so-called organization number specifies the identity of a corporate body. The Swedish Tax Authority (Skatteverket) has a register of all organization numbers used for tax reporting. The numbers are permanent and unique, i.e., one number follows the
} 
organization number can consist of one store or several. SCB provides data at this level based on tax reporting. Financial Statistics (FS) provides input and output measures, and Regional Labor Statistics (RAMS) provides data on wages for all organization numbers, from 1996 to 2002, belonging to SNI code 52.1, "Retail sales in non-specialized stores," which covers the four dominant groups (ICA, Coop, Axfood, and Bergendahls). ${ }^{2}$ Anonymous codes in FS-RAMS entail that we do not know the exact identity of an organization number. Except large entrants, it is therefore not possible to exactly determine which stores in DELFI belong to each organization number in FS-RAMS. In FS-RAMS, entry and exit are defined only on the basis of organization numbers and may not perfectly match those in DELFI. Exit in FS-RAMS may thus be due to re-organizations, for example. For most stores that exit, however, the organization number disappears from FS-RAMS. For our purposes, we estimate productivity for each organization number and year using FS-RAMS and define physical entry of big-box stores based on DELFI. All stores are included in both data sets. In FS-RAMS, we observe the municipality in which each organization number is physically located. If an observation in the data consists of more than one store, we observe total, not average, inputs and outputs. Most importantly, this does not affect the definition of large entrants, which is based on DELFI data. Because large entrants have new organization numbers, we can remove them from FS-RAMS and check that the number and characteristics of large entrants in each local market are consistent with DELFI. Moreover, we can still analyze productivity and exit through the exit of organization numbers in each municipality and year using FS-RAMS. Finally, we associate demographic information (population, population density, average income, and political preferences) from SCB with FS-RAMS and DELFI.

corporate body throughout its whole existence, and two identical organization numbers do not exist. The register contains the date of registration of the organization number and information regarding any exit/bankruptcy (Swedish Tax Authority, 2011).

${ }^{2} \mathrm{SNI}$ (Swedish National Industry) classification codes build on the EU standard NACE. In 2000, Axel Johnson and the D-group (D\&D) merged to form Axfood, initiating more centralized decision-making and more uniformly designed store concepts from 2001 and onwards. 
The number of stores in DELFI decreases over the period from 4,664 to 3,585 , i.e., a 23 percent reduction. In FS-RAMS, the number of observations decreases by about 17 percent (from 3,714 to 3,067). ${ }^{3}$ Because we only observe the total number of unique organization numbers in FSRAMS, we can at most calculate bounds of the number of multi-store units in FS-RAMS through comparison with the total number of single-store units in DELFI. These bounds depend on the nature and combinations of the multi-store units. At one extreme, there is only one multi-store in FS-RAMS, while at another extreme, there are multi-stores consisting of two stores each in FS-RAMS. This implies that the share of single stores in FS-RAMS varies between 75 and 99 percent.

The DELFI data. DELFI Marknadspartner AB collects daily data on retail food stores from a variety of channels: (1) public registers, the trade press, and daily press; (2) the Swedish retailers association (SSLF); (3) Kuponginlösen $\mathrm{AB}$ (which deals with rebate coupons collected by local stores); (4) the chains' headquarters; (5) matching customer registers from suppliers; (6) telephone interviews; (7) yearly surveys; and (8) the Swedish Retail Institute (HUI). Location, store type, owner, and chain affiliation are double-checked in corporate annual reports.

Each store has an identification number linked to its geographical location (address). The twelve store types, based on size, location, product assortment, etc., are hypermarkets, department stores, large supermarkets, large grocery stores, other stores, small supermarkets, small grocery stores, convenience stores, gas-station stores, mini markets, seasonal stores, and stores under construction.

Sales (including VAT) and sales space are collected via yearly surveys. Due to the survey collection, a number of missing values are substituted with the median of other stores of the same type in the same local market. In total, 702 stores have missing sales: 508 in 1996, and 194 in later years. For sales space, all 5,013 values are missing for 1996, and are therefore replaced with the mean of each store's 1995 and 1997 values. In addition,

\footnotetext{
${ }^{3}$ This indicates that entry and exit based on changes in organization numbers in FS-RAMS in some cases differ from entry and exit based on addresses in DELFI due to, e.g., re-organizations.
} 
2,810 missing sales space values for later years are replaced similarly. In total, 698 observations are missing both sales and sales space.

Average sales between 1996 and 2002 is SEK 1.8 million for hypermarkets and SEK 0.8 million for large grocery stores. The standard deviations are 0.9 million and 0.55 million, respectively. Large supermarkets have average sales of SEK 0.64 million; small supermarkets have average sales of SEK 0.25 million. While sales space is largest for hypermarkets, average sales space is 1,500 square meters for large supermarkets and 600 square meters for small supermarkets. Due to the large differences in sales and sales space, it is reasonable to separate small and large supermarkets.

The FS-RAMS data. FS-RAMS contains all registered organization numbers in the different Swedish industries from 1996 to 2002. Value added is defined as total shipments, adjusted for inventory changes, minus costs of materials. Labor is the total number of employees. We deflated sales, value added, wages, and investment by the consumer price index (CPI) from IMF-CDROM 2005.

Capital is constructed using a perpetual inventory method, $K_{t+1}=$ $(1-\delta) K_{t}+\exp \left(i_{t}\right)$, where $\delta$ is the depreciation rate. Because the data distinguish between buildings and equipment (machinery), all capital stock calculations are performed separately for buildings and equipment. Investment measures the difference between the real gross expenditures on capital and real gross retirement of capital. In the paper, we include equipment in the capital stock. Including both equipment and buildings in the capital stock does not change the results, however. As suggested by Hulten and Wykoff (1981), buildings depreciate at a rate of 0.0361 and equipment at 0.1179. ${ }^{4}$ To construct a capital series using the perpetual inventory method, an initial capital stock is needed. We set the initial capital stock to its first occurrence in FS-RAMS, defining entry as the first year in FS (some of the stores have been in FS since 1973), and assume the entire book value of capital was put in place in the previous year (Olley and Pakes, 1996).

Data limitations constraint us from comparing the capital stock and the number of square meters at the store level. However, we can compute the

\footnotetext{
${ }^{4}$ These depreciation rates are used by other Swedish studies.
} 
correlation between capital stock and sales space across local markets and years. The correlation between capital stock (equipment) and sales space $\left(m^{2}\right)$ is 0.63 , and the correlation between total capital stock (buildings and equipment) and sales space $\left(m^{2}\right)$ is 0.65 . Given these high correlations and because of the importance of investment in technology in retail (such as scanner techniques and credit card machines) and because there are no notable differences in the productivity estimates, we only report results using capital stock based on equipment.

\section{Section B: Additional remarks on the iden- tification of the impact of large entrants on productivity and de- mand}

Our main assumption is that the current number of large entrants $e_{m t}^{L}$ impacts prices (demand effect), and the number of previous large entrants $e_{m t-1}^{L}$ impacts stores' productivity $\omega_{j t}$. In other words, we expect a negative impact of $e_{m t}^{L}$ on sales and a positive impact of $e_{m t-1}^{L}$ on productivity. First, an additional large entrant in the market decreases the quantity sold (competition effect) and might force stores to set lower prices to compensate for the immediate competition effect. Second, previous large entrants $e_{m t-1}^{L}$ positively impact current productivity (X-inefficiency), i.e., $e_{m t-1}^{L}$ increases quantity sold by stores $q_{j t}$. The above assumption rules out the effect of $e_{m t-1}^{L}$ on demand (prices). If previous large entrants still impact current prices (lagged demand effect), stores decrease their prices, which in turn increases quantity sold $q_{j t}$. Therefore, $q_{j t}$ can increase because of both productivity and demand.

Lack of product-level data in retail constrains us to identify these two effects separately. If we had price data for each store, we could estimate demand and supply separately, which would allow us to distinguish between 
the impact of large entrants on demand and on supply without relying on a timing assumption. However, the retail market is complex due to its multistore, multi-product, and multi-location nature. Owing to this complexity and difficulties in defining a "price" measure (because stores offer different product baskets), this type of analysis of retail markets will always require additional assumptions (e.g., a timing assumption) to separately identify the effect of large stores on demand and on supply. Hence, even if prices are observed, the use of a product basket necessitates assumptions. As a matter of fact, the researcher will have to choose among sets of assumptions in accordance with the specific application and data available.

Indeed, a common data constraint in the study of retail is a lack of detailed price information. Because individual stores determine prices in Sweden and because our ability to measure prices is limited, an additional timing assumption is necessary. In Sweden, we believe it is reasonable to assume that, if individual stores adjust their prices in response to a large entrant, this will occur within the year that large entry takes place. Previous research on Swedish data has documented that large entrants have only small effects on prices of rival stores (Asplund and Friberg, 2002). The cost of adjusting prices is low, and there is a high frequency of price changes of retail food products (we abstract from promotions and discounts, etc.). Our model captures the average price effect in the year of entry, i.e., the main shift in price that may occur after large entry. We argue that this is a valid time period in which to measure the "main demand response" as a consequence of large entry.

Reduced-form regressions. Table B.1 shows median local market characteristics for socialist markets with large entrants and non-socialist markets without large entrants. There are 1-6 socialist markets with large entrants and 82 to 147 non-socialist markets without large entrants during the study period. Socialist markets with large entrants are larger markets (population), and have lower population density than non-socialist markets without large entrants. Both market groups have about the same median income. In Sweden, income is relatively homogeneous across different geographical regions. However, we control for all these observed local market 
characteristics when estimating productivity.

Table B.2 presents reduced-form regressions for the endogenous variable $e_{m t}^{L}$ to show the relevance of the instruments. The share of non-socialist seats in local markets and the number of large entrants in other municipalities in the same country (neighboring markets) have a positive and statistically significant effect on the number of large entrants after controlling for observed and unobserved market characteristics. In the empirical implementation presented in Section 5 in the paper, we use both the number of large entrants in other local markets (i.e., Hausman type instruments) and the share of non-socialist seats as instruments for large entrants. Hausman type instruments are widely used but controversial (Hausman, 1997). They are used because they are always available. In our context, the number of large entrants in other markets is an appropriate instrument if the number of large entrants in other markets reflects common trends or demand shocks only specific to large entrants, e.g., unobserved advertising. Our productivity results are robust to using both these instruments. We acknowledge that the proposed instruments are not perfect when there are correlated unobservables across markets. We believe, however, that they are the best instruments given the available data and modeling framework, and they have been used extensively in the empirical literature (see, e.g., Hausman, 1997; Bertrand and Kramarz, 2002; Petrin and Train, 2010; Schivardi and Viviano, 2011; Maican and Orth, 2015). In addition, we should recall that one of the objectives of our structural framework is to isolate demand shocks (lower prices, new demand from product differentiation) associated with current large entrants from the productivity measure.

Table B.3 presents linear least squares (OLS) and two-stage least squares (2SLS) regressions of reduced-form production function equation that include both current and previous large entrants. In all specifications, the coefficients for current and previous large entrants are not statistically significant at the 10 percent level. ${ }^{5}$ The 2 SLS specifications $\left(\mathcal{S}_{2}, \mathcal{S}_{4}, \mathcal{S}_{5}\right.$, and $\mathcal{S}_{6}$ ) use the share of non-socialist seats and the previous number of large

\footnotetext{
${ }^{5}$ In 2SLS regressions, it is well know that standard errors "have a tendency to be large" (Wooldridge, 2002, p.102).
} 
stores in neighboring municipalities as instruments to control for endogeneity of the current number of large entrants (Hausman type instruments). The coefficient for $e_{m t}^{L}$ changes sign when controlling for endogeneity of the actual number of large entrants. One aim of our structural framework in Section 3 is to isolate demand shocks (lower prices, new demand from product differentiation) associated with current large entrants from the productivity measure. Most importantly, in our empirical setting, the coefficient for $e_{m t-1}^{L}$ is positive in all regressions, i.e., our hypothesis is not rejected. In specification $\mathcal{S}_{6}$, we use the previous number of large stores in neighboring municipalities as instruments to control for endogeneity in the first step of our modeling framework. We also test for the presence of weak instruments, using a partial-F test (Staiger and Stock, 1997). The results indicate that the instruments are not weakly correlated with the current number of large entrants. Therefore, the findings suggest that we cannot reject the timing assumption regarding the number of large entrants. However, these results should be interpreted with care, as the regressions do not control for other simultaneity and selection bias issues (specific to production functions).

If the timing assumption with respect to large entrants does not hold, the coefficient for lagged large entry will capture the "net effect" of both productivity and (lagged) demand. A positive coefficient on lagged large entry implies higher output due to productivity improvements in the next period. Provided this coefficient is positive, however, the productivity effect outweighs the (negative) demand effect. Importantly, the presence of lagged demand effects imply that the "true" impact of large entrants on productivity will be larger than we observe.

Marginal effects of large entrants on productivity. The effect of large entrants on productivity is computed using the endogenous Markov process. The total change in future productivity is given by

$$
d \omega_{j t}=h_{\omega} d \omega_{j t-1}+h_{e^{L}} d e_{m t-1}^{L}
$$


where $h_{\omega}=\partial h(\cdot) / \partial \omega_{j t-1}$ is the marginal effect of previous productivity on future productivity and $h_{e^{L}}=\partial h(\cdot) / \partial e_{m t-1}^{L}$ is the marginal effect of an additional large entrant on future technical productivity. Thus, the total change in productivity due to large entrants is

$$
\frac{d \omega_{j t}}{d e_{m t-1}^{L}}=h_{\omega} \frac{d \omega_{j t-1}}{d e_{m t-1}^{L}}+h_{e^{L}} .
$$

In the case of true technical productivity, i.e., recovered from a production function based on quantities, the immediate effect of large entrants on productivity is zero $\left(d \omega_{j t-1} / d e_{m t-1}^{L}=0\right)$. The ratio $d \omega_{j t-1} / d e_{m t-1}^{L}$ is different from zero when we do not remove the contemporaneous effect of large entrants on prices and/or when large entrants enter expanding markets $\left(d \mathbf{x}_{m t-1} / d e_{m t-1}^{L} \neq 0\right)$. This explains differences in the effect of large entrants across specifications that omit to control for the effect of large entrants on prices.

Table B.1: Median of local market characteristics: Large entrants and political preferences

\begin{tabular}{|c|c|c|c|c|c|c|}
\hline Year & 1997 & 1998 & 1999 & 2000 & 2001 & 2002 \\
\hline \multicolumn{7}{|c|}{ A. Markets with socialist majority and large entrants } \\
\hline No. of stores & 35.00 & 35.00 & 20.00 & 22.00 & 22.00 & 20.00 \\
\hline No. of all entrants & 2.00 & 2.00 & 3.00 & 1.00 & 1.00 & 1.00 \\
\hline No. of all exits & 2.00 & 2.00 & 2.00 & 3.00 & 1.00 &.-- \\
\hline Population & $43,646.00$ & $49,219.00$ & $24,059.00$ & $20,037.00$ & $17,619.00$ & $7,949.00$ \\
\hline Population density & 69.30 & 36.98 & 26.24 & 9.77 & 7.25 & 1.38 \\
\hline Per capita income & 146.45 & 158.55 & 153.10 & 170.70 & 168.40 & 155.60 \\
\hline Total no. of markets & 6 & 4 & 4 & 3 & 6 & 1 \\
\hline \multicolumn{7}{|c|}{ B. Markets with non-socialist majority but without large entrants } \\
\hline No. of stores & 18.00 & 18.00 & 17.00 & 16.00 & 14.00 & 15.00 \\
\hline No. of all entrants & 0.00 & 1.00 & 1.00 & 0.00 & 0.00 & 0.00 \\
\hline No. of all exits & 0.00 & 1.00 & 1.00 & 2.00 & 0.00 &.-- \\
\hline Population & $28,835.00$ & $25,152.00$ & $20,262.00$ & $20,406.00$ & $19,967.00$ & $22,790.00$ \\
\hline Population density & 75.46 & 80.51 & 45.05 & 45.32 & 42.67 & 48.28 \\
\hline Per capita income & 150.40 & 156.05 & 159.15 & 166.15 & 172.90 & 180.10 \\
\hline Total no. of markets & 83 & 82 & 134 & 132 & 133 & 147 \\
\hline \multicolumn{7}{|c|}{$\begin{array}{l}\text { NOTE: } 1996 \text { is omitted because entrants are not observed. The number of municipalities, considered as local } \\
\text { markets, increase from } 288 \text { to } 290 \text { due to three municipality break-ups during the study period. A non-socialist } \\
\text { majority is defined based on the share of seats held by the Moderate Party, Christian Democrats, and the Liberal } \\
\text { Party. The Center Party is excluded because of its focus on rural areas and because the cut-off share is set at } \\
\text { 0.3. Data on stores, entrants and exits come from DELFI. Population density is defined as total population per } \\
\text { square kilometer within a municipality. }\end{array}$} \\
\hline
\end{tabular}


Table B.2: The relation between large entrants, political preferences, and large entrants in the neighboring markets

\begin{tabular}{|c|c|c|c|c|}
\hline Panel A: Large entrants and & $\begin{array}{c}\text { eferences } \\
\text { (1) }\end{array}$ & $(2)$ & $(3)$ & $(4)$ \\
\hline Local political preferences & $\begin{array}{c}0.222 \\
(0.058)\end{array}$ & $\begin{array}{c}0.198 \\
(0.059)\end{array}$ & $\begin{array}{c}0.579 \\
(0.214)\end{array}$ & $\begin{array}{c}0.695 \\
(0.304)\end{array}$ \\
\hline Log of population & & & & $\begin{array}{l}-0.037 \\
(0.766)\end{array}$ \\
\hline Log of population density & & & & $\begin{array}{c}0.401 \\
(0.684)\end{array}$ \\
\hline $\log$ of income & & & & $\begin{array}{l}-0.050 \\
(0.136)\end{array}$ \\
\hline Year dummies & No & Yes & No & No \\
\hline Market dummies & No & No & Yes & Yes \\
\hline Root of mean squared errors & 0.285 & 0.284 & 0.248 & 0.248 \\
\hline$R^{2}-a d j$ & 0.010 & 0.018 & 0.096 & 0.095 \\
\hline Partial F-test & . & 15.95 & 9.146 & 6.616 \\
\hline (p-value) & . & $(0.000)$ & $(0.002)$ & $(0.010)$ \\
\hline Number of observations & 1,977 & 1,977 & 1,977 & 1,977 \\
\hline \multicolumn{5}{|c|}{ Panel B: Large entrants and the number of large entrants in neighboring market } \\
\hline No. of large entrants in & 0.012 & 0.005 & 0.013 & 0.012 \\
\hline the neighboring markets & $(0.005)$ & $(0.005)$ & $(0.006)$ & $(0.006)$ \\
\hline Log of population & & & & $\begin{array}{l}-0.023 \\
(0.767)\end{array}$ \\
\hline Log of population density & & & & $\begin{array}{c}0.386 \\
(0.685)\end{array}$ \\
\hline Log of income & & & & $\begin{array}{c}0.142 \\
(0.098)\end{array}$ \\
\hline Year dummies & No & Yes & No & No \\
\hline Market dummies & No & No & Yes & Yes \\
\hline Root of mean squared errors & 0.286 & 0.285 & 0.248 & 0.249 \\
\hline$R^{2}-a d j$ & 0.003 & 0.009 & 0.094 & 0.094 \\
\hline Partial F-test & . & . & 5.744 & 4.546 \\
\hline (p-value) & . & . & $(0.016)$ & $(0.033)$ \\
\hline Number of observations & 1,977 & 1,977 & 1,977 & 1,977 \\
\hline
\end{tabular}

NOTE: The dependent variable is the number of large entrants. An OLS

estimator is used. Standard errors robust to heteroscedasticity are in parentheses. Partial F-tests are used to determine whether political preferences or the number of large entrants in neighboring markets are weak instruments (Staiger and Stock, 1997) for large entrants. 
Table B.3: Reduced form regressions: The impact of current and previous large entrants on value-added

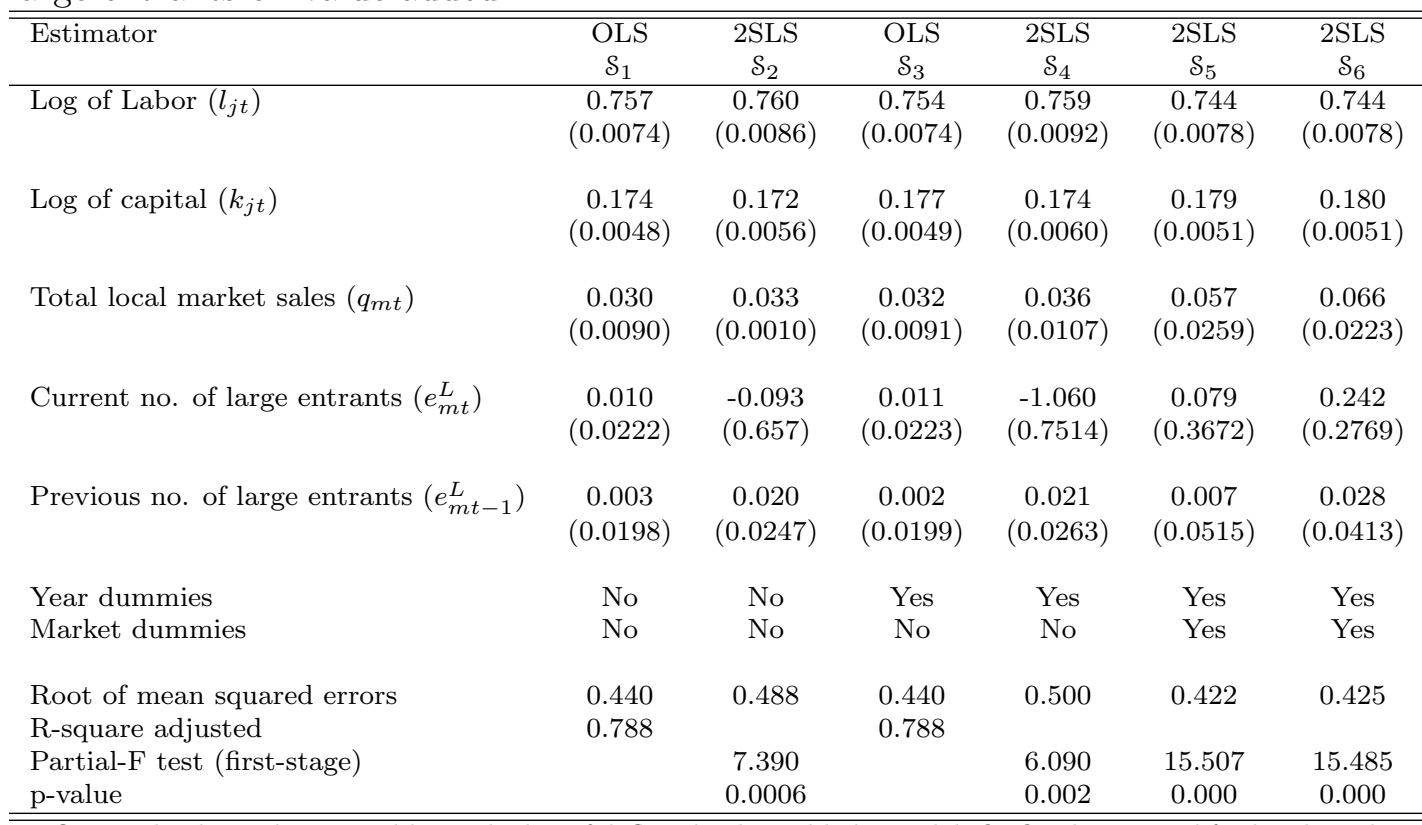

NOTE: The dependent variables is the log of deflated value-added. Models $\mathcal{S}_{1}-\mathcal{S}_{6}$ also control for local market characteristics (population, population density). The largest cities, Stockholm, Gothenburg, and Malmo, are excluded. Models $\mathcal{S}_{2}, \mathcal{S}_{4}, \mathcal{S}_{5}$ use the share of the non-socialist seats and the previous number of large entrants in neighboring municipalities as instrumental variables for the actual number of large entrants. Model $\mathcal{S}_{6}$ uses the current and previous numbers of large entrants in neighboring municipalities and the share of non-socialist seats at the municipality level as instrumental variables for the current number of large entrants. 


\section{Section C: Wage variation}

We run reduced-form regressions that control for store and market characteristics and market fixed effects. We use three measures of store size: the number of employees, capital stock and a dummy variable for being a large store. The local market controls include population, population density and income. The model would be improved if we could add chain/firm dummies in the regressions, however. Statistics Sweden (SCB) does not disclose the name or identity of organization numbers in FS-RAMS for confidentiality reasons, and the DELFI data do not have wage (input/output) information. FS-RAMS protects individual stores by keeping them anonymous (Answer to Comment 1). However, we have information about the share of employees with a university degree in FS-RAMS.

Table C.1 below shows results for five different specifications using data for the year 2000 and store-specific wages as the dependent variable. Market dummy variables alone explain only 9.7 percent of the variation in wages (column 1). By adding capital stock and a dummy for large stores and local market controls, we can explain 14.2 percent of the wage variation (column 2). The coefficients of capital and the large store dummy are both positive and statistically significant at conventional levels. By including labor (number of employees) as additional measure of store size, the variation in wages explained by the covariates increases to 15.7 percent (column 3). We additionally control for the share of employees with a university degree (columns 4 and 5). The coefficient of education is negative but not statistically significant, even at the 10 percent level, and the adjusted $R^{2}$ remains approximately the same, i.e., 8.9 percent and 14.3 percent. One plausible explanation of the negative sign is that more educated employees are likely to be students who work and/or have a summer job, and they have a negative impact on average store wages. Overall, the results indicate that there are other unobserved factors at the store level that explain the variation in the store wages, such as bargaining negotiations and experience (Ackerberg et al., 2007). The results presented for the cross-section of data for year 2000 are robust when using data for the full time period 
1996-2002 (Table C.2).

The mean share of employees with at least three years of university education is 0.064 using the data from FS-RAMS during 1996-2002. We use a one-sided t-test to test whether the mean share of educated employees (defined in FS-RAMS) is the same for small and large stores, i.e., 0.064. The results show that we cannot reject the null hypothesis that the means are equal to 0.064 for both small and large stores. These findings suggest no systematic differences in hiring educated workers between small and large stores.

Our measure of wages is less susceptible to measurement errors due to reporting. The FS-RAMS dataset contains full-time adjusted wages for all organization numbers in the Swedish retail food market. Wages are aggregated from a very detailed register database containing individual information for each person in Sweden and are reported as averages in FS-RAMS. Wages come from register data based on tax reporting and are provided by Statistics Sweden (SCB). These data additionally account for part-time work in an accurate way (we observe full-time adjusted wages).

The Swedish labor market regulations and the presence of labor unions imply that we are unlikely to observe stores with wages below union levels or illegal contracts that could reduce wages (the cost of labor). The players in our data have been operating for a long time, store types and formats are similar across groups, and we do not expect systematically lower wages at some stores from a particular firm. Minimum wages are imposed by strong labor unions. In addition, individual employees have individual wages and meet with their employer every year for a private meeting regarding wages and development. The Swedish Commercial Employees' Union ("Handels") is the labor union representing a majority of members in the retail sector. Handels was founded in 1906 and has 149,000 members. Other sectors include florists, hairdressers, storage and warehouse personnel, opticians, and watchmakers. Handels negotiates agreements for fair pay and working conditions. Consequently, the information regarding employment conditions (for example, how wages are decided, the availability of part-time work, the education of employees and the quality of contracts etc.) is quite good 
for the Swedish retail food market. These labor friendly conditions can be contrasted with Wal-Mart. Wal-Mart allegedly has debated offering below union wages and illegal contracts, which, if true, reduces the cost of labor without reducing labor inputs and hence affects productivity. We do not expect this situation to be a concern in our data. Swedish labor market regulations additionally imply that it is unlikely that a full-time employee works more than 8 hours per day. That is, we do not expect overtime to play a role in our wage measurement. In addition, a majority of stores are open from 8:00 to 22:00 or 9:00 to 21:00. Although there has been a tendency toward longer hours of operation over time, there are no differences across stores belonging to different groups (stores compete in a number of similar store formats). While the total number of full-time employees increased over time from 74,100 to 80,931 (Table 1 in the paper), the trend of larger but fewer stores (consolidation) in local markets (municipalities) indicates that this increase in employees is not driven by longer hours of operation. Therefore, we do not expect systematic differences in hours to cause compositional effects.

Given the data available, we can proxy for "observed worker quality" using level of education. Because labor cost is reported as the full-time adjusted average wage per worker, we may also measure unobserved employee quality. Because we do not directly observe employee quality and some stores might hire high quality employees, the unobserved quality affects productivity $\omega_{j t}$. Worker quality is unobserved by the researcher but is observed by stores, so we have two unobservables, which complicates the estimation. Ackerberg et al. (2007) provide a detailed discussion about the unobserved quality of labor when estimating production functions. In our model, the observed variation in store wages is due to differences in exogenous market conditions, and not due to differences in unobserved employee quality. The findings on the wage variation suggest that this assumption is not restrictive in our application. A small part of wage variation being caused by employee quality would appear in the productivity measure, but the remaining variation in wages helps us to identify the input coefficients. Importantly, our measure of wages is an accurate reflection of exogenous 
changes in the price of labor, because the 22 percent growth in retail wagebill during the period (Table 1 in the paper) is similar to the 24 percent growth in aggregate real wages in Sweden (Statistics Sweden).

Table C.1: Reduced form regressions: Store level wages rates in year 2000

\begin{tabular}{lccccc}
\hline \hline & $(1)$ & $(2)$ & $(3)$ & $(4)$ & $(5)$ \\
\hline Log no. of labor & & & 0.089 & & \\
& & & $(0.013)$ & & 0.072 \\
Log of capital & & $(0.007)$ & 0.035 & & $(0.009)$ \\
& & 0.058 & -0.011 & & $0.007)$ \\
Large store & & $(0.039)$ & $(0.040)$ & & $(0.039)$ \\
& & & -0.079 & -0.048 \\
Share with university degree & & & & $(0.063)$ & $(0.061)$ \\
& & & & yes & yes \\
& no & yes & yes & yes & yes \\
Local market characteristics & yes & yes & & & \\
Local market fixed effect & & & & & \\
& 0.097 & 0.142 & 0.157 & 0.089 & 0.143 \\
R-squared adjusted & & & & \\
Root of mean squared errors & 0.456 & 0.453 & 0.453 & 0.465 & 0.453 \\
\hline \hline
\end{tabular}

NOTE: The dependent variable is the log of the average store wages in FS-RAMS. Standard errors are in parentheses. Labor is measured as the number of full-time adjusted employees. "Large store" is a dummy variable that defines a large store in FS-RAMS based on information in DELFI. "Share with university degree" is the share of employees with a university degree and requires at least 3 years of education in FS-RAMS. Local market characteristics include population, population density, income and the number of large entrants.

Table C.2: Reduced form regressions: Store level wages rates 1996-2002

\begin{tabular}{lccccc}
\hline \hline & $(1)$ & $(2)$ & $(3)$ & $(4)$ & $(5)$ \\
\hline Log no. of labor & & & 0.094 & & \\
& & 0.081 & $(0.004)$ & & 0.080 \\
Log of capital & & $(0.002)$ & $(0.003)$ & & $(0.002)$ \\
& & 0.033 & -0.047 & & 0.033 \\
Large store & & $(0.013)$ & $(0.001)$ & & $(0.013)$ \\
& & & -0.079 & -0.053 \\
Share with university degree & & & & $(0.023)$ & $(0.022)$ \\
& & & & yes & yes \\
Local market characteristics & no & yes & yes & yes & yes \\
Local market fixed effect & yes & yes & yes & yes & yes \\
Year fixed effect & yes & yes & & & \\
& & & & & \\
R-squared adjusted & 0.052 & 0.109 & 0.128 & 0.052 & 0.109 \\
Root of mean squared errors & 0.480 & 0.465 & 0.460 & 0.480 & 0.465 \\
\hline \hline
\end{tabular}

NOTE: The dependent variable is the log of average store wages in FS-RAMS. Standard errors are in parentheses. Labor is measured as the number of full-time adjusted employees. "Large store" is a dummy variable that defines a large store in FS-RAMS based on information in DELFI. "Share with university degree" is the share of employees with a university degree and requires at least 3 years of education in FS-RAMS. Local market characteristics include population, population density, income and the number of large entrants. 


\section{Section D: Estimation of the productivity pro- cess}

Nonparametric labor demand function. Sections 3 and 5 in the paper describe the identification and estimation of store productivity using invertibility property of the nonparametric labor demand function. Conditional on capital, profit maximizing behavior must lead to that more productive firms use more labor (number of employees). We imagine a story where increases in productivity result in an increase in the marginal product of labor. This in turn leads firms to increase output, which leads to more labor use. We show the conditions that are necessary for monotonicity of the labor demand function under imperfect competition, where stores take input prices as given (e.g., wage $w$ ). We assume the industry is competitive if stores take input prices and the output price for the homogeneous good as given. Current demand shifters are assumed to not be affected by current productivity. To keep the notation short, we ignore the notation of the exogenous variables to stores $\left(\mathbf{x}, e^{L}\right)$ that affect demand, and store index $j$ (in the main text) .

Assumption. Stores sell products and services following the technology $Q=F(K, L, \omega): \mathbb{R}^{3} \rightarrow \mathbb{R}$, which is twice continuously differentiable in labor $(L)$ and $F_{L \omega}, F_{L}$, and $F_{\omega}$ exist for all values $(K, L, \omega) \in \mathbb{R}^{3}$. The industry is competitive and (i) current investment does not respond to current productivity; or (ii) current investment does not enter in current capital stock; or (iii) current demand shifters are not affected by current productivity. Store productivity is observed before the choice of labor is made.

We treat capital and demand shifters as fixed, and assume labor responds to the productivity. By adding more regularity conditions, it is possible to show the following result when capital and demand shifters also respond to $\omega$.

Lemma. Under imperfect competition with downward sloping demand curve $p\left(\sum Q\right)$ with the demand elasticity $\eta<-1$, if $F_{L \omega}+(1 / \eta)(1 / Q) F_{\omega} F_{L}>$ 
0 everywhere, then the labor demand $L(\omega ; w, K)$ is strictly increasing in $\omega$. Proof: The profit maximizing store has a labor demand function that satisfies the first-order condition:

$$
p(\cdot)\left(1+\frac{1}{\eta}\right) \frac{\partial F}{\partial L}=\lambda w
$$

where $\lambda$ is the Lagrange multiplier. To obtain an expression for the derivative of the labor demand function with respect to productivity, we compute the partial derivative of the first-order condition [FOC] in equation (1) with respect to productivity $\omega$. The change in output price due to productivity evaluated using the optimal labor demand function is given by

$$
\frac{\partial p(\cdot)}{\partial \omega}=\frac{\partial p(\cdot)}{\partial Q} \frac{\partial F}{\partial L} \frac{\partial L}{\partial \omega}+\frac{\partial p(\cdot)}{\partial Q} \frac{\partial F}{\partial \omega} .
$$

Using the derivative of the FOC with respect to $\omega$, we obtain

$$
\frac{\partial L}{\partial \omega}=\frac{p(\cdot)\left[\frac{\partial^{2} F}{\partial L \partial \omega}+\frac{1}{\eta} \frac{1}{Q} \frac{\partial F}{\partial \omega} \frac{\partial F}{\partial L}\right]}{-\frac{1}{\eta} \frac{p(\cdot)}{Q}\left(\frac{\partial F}{\partial L}\right)^{2}}
$$

where $\eta=\frac{\partial Q}{\partial p}: \frac{Q}{p}$ and $\eta<-1$. Note that $-\frac{1}{\eta} \frac{p(\cdot)}{Q}\left(\frac{\partial F}{\partial L}\right)^{2}>0$ holds everywhere. Therefore, we find that

$$
\operatorname{sign}\left(\frac{\partial L}{\partial \omega}\right)=\operatorname{sign}\left(\left[\frac{\partial^{2} F}{\partial L \partial \omega}+\frac{1}{\eta} \frac{1}{Q} \frac{\partial F}{\partial \omega} \frac{\partial F}{\partial L}\right]\right)
$$

For example, under the Cobb-Douglas technology, we have

$$
\operatorname{sign}\left(\frac{\partial L}{\partial \omega}\right)=\operatorname{sign}\left(\beta_{l} \frac{Q}{L}(1+1 / \eta)\right)
$$

This implies that under Cobb-Douglas technology, we have $\frac{\partial L}{\partial \omega}>0$, i.e., the labor demand function is strictly increasing in productivity. This condition holds for the model presented in Section 3 in the paper using the parametric labor demand function (see footnote 28 in the paper and online Appendix E). Since $\left[\frac{\partial^{2} F}{\partial L \partial \omega}+\frac{1}{\eta} \frac{1}{Q} \frac{\partial F}{\partial \omega} \frac{\partial F}{\partial L}\right]>0$ holds everywhere, under the regularity 
conditions on $F(\cdot)$ that ensure that the Fundamental Theorem of Calculus holds everywhere, we have

$$
\int_{\omega_{1}}^{\omega_{2}} \frac{\partial L}{\partial \omega}(\omega ; w, K) P(d \omega \mid K)>\int_{\omega_{1}}^{\omega_{2}} 0 P(d \omega \mid K)=0 .
$$

Therefore, we have $L\left(\omega_{2} ; w, K\right)>L\left(\omega_{1} ; w, K\right)$, if $\omega_{2}>\omega_{1}$. It is important to point out that it is necessary that labor's marginal product is increasing in productivity in order to show that the labor demand function is increasing in productivity.

Estimates of the nonlinear productivity process. For brevity, Table 6 in the paper only shows a summary of the estimated productivity process. In this section, we provide additional details and show all coefficients of the polynomial expansion of the estimated productivity process. 
Table D.1: Nonlinear estimation of the productivity process using polynomial expansion of 3rd order

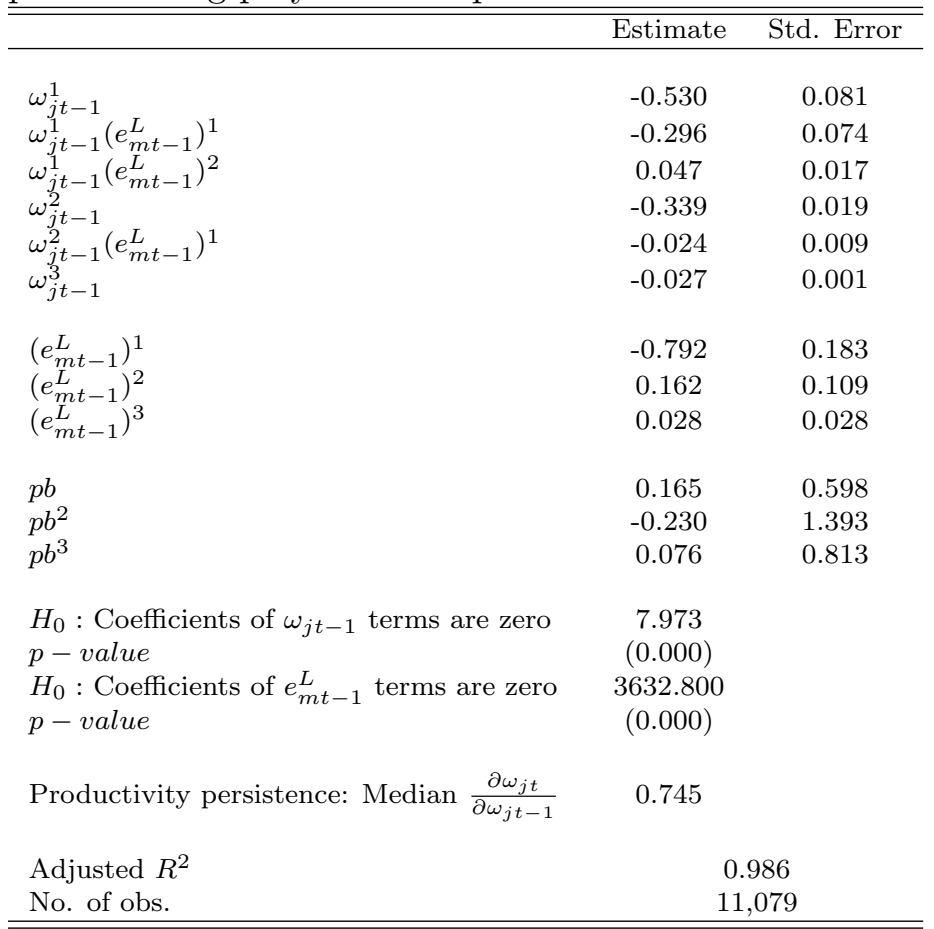

NOTE: Intercept is included. Productivity is recovered from the labor demand function using the semiparametric two-step approach controls for simultaneity, selection, and imperfect competition (see Sections 3 and 5 in the paper). We control for endogeneity of large entrants, market output and wages in the first stage. The largest cities Stockholm, Gothenburg, and Malmo are excluded. 


\section{Section E: Parametric approach}

Assuming Cobb-Douglas technology and that labor is a static and variable input chosen based on current productivity, a parametric expression for productivity can be derived from the inverse labor demand function (Doraszelski and Jaumandreu, 2013)

$$
\begin{aligned}
\omega_{j t} \equiv \tilde{l}_{t}^{-1}(\cdot)= & \frac{\eta}{1+\eta}\left[\delta_{1}+\left[\left(1-\beta_{l}\right)-\frac{1}{\eta} \beta_{l}\right] l_{j t}+w_{j t}-p_{m t}-\left(1+\frac{1}{\eta}\right) \beta_{k} k_{j t}\right. \\
& \left.+\frac{1}{\eta} q_{m t}+\frac{1}{\eta} \beta_{e} e_{m t}^{L}+\frac{1}{\eta} \mathbf{x}_{m t}^{\prime} \boldsymbol{\beta}_{x}\right]
\end{aligned}
$$

where $\delta_{1}=-\ln \left(\beta_{l}\right)-\ln \left(1+\frac{1}{\eta}\right)-\ln E\left[\epsilon_{j t}\right]$. The value-added generating function given in Section 3 is

$$
\begin{aligned}
y_{j t}= & \left(1+\frac{1}{\eta}\right)\left[\beta_{l} l_{j t}+\beta_{k} k_{j t}\right]-\frac{1}{\eta} q_{m t}-\frac{1}{\eta} \beta_{e} e_{m t}^{L}-\frac{1}{\eta} \mathbf{x}_{m t}^{\prime} \boldsymbol{\beta}_{x} \\
& +\left(1+\frac{1}{\eta}\right) h\left(\omega_{j t-1}, e_{m t-1}^{L}\right)+\left(1+\frac{1}{\eta}\right) \xi_{j t}+\epsilon_{j t} .
\end{aligned}
$$

The assumptions under the nonparametric function apply also in the parametric case (Cobb-Douglas), i.e., scalar unobservable, monotonicity, variation in wages, and timing assumptions. Identification is based on variation in store wages (and prices if available), and variation in large entrants across markets and time. That each store sets wages guarantees our identification strategy. To estimate (8), we use the sieve minimum distance procedure proposed by Ai and Chen (2003) and Newey and Powell (2003). We approximate $h(\cdot)$ by a third-order polynomial expansion in $\omega_{j t-1}$, given by $(7)$, and $e_{m t-1}^{L}$. We use a tensor product polynomial series of capital $\left(k_{j t}\right)$, labor $\left(l_{j t-1}\right)$, wages $\left(w_{j t}\right)$, the consumer price index for food products $\left(p_{m t}\right)$, actual and previous large entrants $\left(e_{m t}^{L}, e_{m t-1}^{L}\right)$, and demand shifters $\left(\mathbf{x}_{m t-1}\right)^{6}$

Estimation results. For robustness, we also consider EDJ $\mathrm{J}_{l m}$ which is the implementation of using a parametric labor demand function as a proxy for

\footnotetext{
${ }^{6}$ Additional details about identification and estimation are available from authors. A crucial difference from the nonparametric setup is that the moments used to identify the parameters in (8) are formed on the sum of i.i.d. shocks $\left((1+1 / \eta) \xi_{j t}+\epsilon_{j t}\right)$ instead of $\xi_{j t}$. The parameters $\left(\boldsymbol{\beta}, h_{H}\right)$ are then jointly estimated using GMM.
} 
productivity, including previous large entrants in the productivity process and controlling for prices and local market characteristics (Doraszelski and Jaumandreu, 2013). A major difference to our main specification is that estimation occurs in one step. The estimated results are in Table E.1. The returns to scale is 1.065 . The coefficients of labor is 0.408 and the one on capital 0.200 . The demand elasticity is -2.186 and the markup 1.842 .

Test of static labor. In the parametric specification $\mathrm{EDJ}_{l m}$, we test the validity of our assumption that labor is static. If the inverse labor demand function is misspecified, the labor coefficient in the value-added generating function differs from the one in the inverse labor demand function. We estimate the restricted and unrestricted models. Then we compute the GMM distance statistic, $D_{N}=N *\left[Q_{N}\left(\beta_{\text {restricted }}\right)-Q_{N}\left(\beta_{\text {unrestricted }}\right)\right]$, to test the null of equal labor coefficients. The null is accepted for $\mathrm{EDJ}_{l m}$, i.e., our assumption of static labor is valid.

Results: large entry, productivity and exit. Table E.3 shows results from the exit regressions based on productivity in estimated by $\mathrm{EDJ}_{l m}$. Based on the pure stopping rule, the coefficient of large entrants is positive but not significant (column 1). The coefficient of the interaction term between large entrants and productivity dummies is positive but not jointly significant with the coefficient of large entry for p10 and p25 (p50-75 as reference group). The corresponding coefficient is negative and jointly significant for p90. The probability to exit is about 0.001 lower for stores in the top part of the productivity distribution than for those in the middle. 
Table E.1: Value-added generating function estimates: parametric approach

\begin{tabular}{|c|c|c|}
\hline & $E D J_{l m}$ & $E D J_{l m e}$ \\
\hline Log no. of labor & $\begin{array}{c}0.408 \\
(0.004)\end{array}$ & $\begin{array}{c}0.413 \\
(0.004)\end{array}$ \\
\hline Log of capital & $\begin{array}{c}0.200 \\
(0.003)\end{array}$ & $\begin{array}{c}0.201 \\
(0.003)\end{array}$ \\
\hline Market output $\left(-\frac{1}{\eta}\right)$ & $\begin{array}{c}0.457 \\
(0.004)\end{array}$ & $\begin{array}{c}0.458 \\
(0.003)\end{array}$ \\
\hline Number of large entrants & $\begin{array}{l}-0.0009 \\
(0.0001)\end{array}$ & $\begin{array}{l}-0.0009 \\
(0.0001)\end{array}$ \\
\hline Population growth & $\begin{array}{c}0.498 \\
(0.014)\end{array}$ & $\begin{array}{c}0.499 \\
(0.007)\end{array}$ \\
\hline Log of population density & $\begin{array}{c}0.113 \\
(0.002)\end{array}$ & $\begin{array}{c}0.106 \\
(0.001)\end{array}$ \\
\hline Income growth & $\begin{array}{c}0.488 \\
(0.004)\end{array}$ & $\begin{array}{c}0.496 \\
(0.004)\end{array}$ \\
\hline Scale $\left(\beta_{l}+\beta_{k}\right)$ & 1.065 & 1.072 \\
\hline Demand elasticity $(\eta)$ & -2.186 & -2.181 \\
\hline $\operatorname{Markup}\left(\frac{\eta}{1+\eta}\right)$ & 1.842 & 1.846 \\
\hline Sargan (p-value) & 0.0927 & 0.0910 \\
\hline No. of obs. & 11,079 & 11,079 \\
\hline
\end{tabular}

NOTE: The dependent variable is log of deflated value added. Labor is measured as number of full-time adjusted employees. All regressions include year dummies. In all specifications that control for imperfect competition, reported parameters include elasticity, i.e., $\left(1+\frac{1}{\eta}\right) \beta_{l}$ for labor, $\left(1+\frac{1}{\eta}\right) \beta_{k}$ for capital, $-\frac{1}{\eta} \beta_{x}$ for exogenous demand shifters, and $-\frac{1}{\eta} \beta_{e}$ for large entry. Both EDJ specifications include previous large entrants in the productivity process, and use previous capital stock and labor as instruments. $E D J_{l m}$ is one-step estimation using a parametric labor demand function and controlling for imperfect competition. $E D J_{l m e}$ is one-step estimation using a parametric labor demand function and controlling for imperfect competition and endogeneity of wages and large entrants. Reported standard errors (in parentheses) are robust to heteroscedasticity. $E D J_{l m e}$ uses the share of non-socialist seats in the local government and the previous number of large entrants in the neighboring markets as instrument for current large entry. Two-step GMM is used for estimation. Market output is measured as the market share weighted output in the municipality. Mark-up is defined as price over marginal cost. 
Table E.3: Regression results parametric approach: Exit

\begin{tabular}{|c|c|c|}
\hline \multirow{2}{*}{ I } & \multicolumn{2}{|r|}{$E D J_{l m}$} \\
\hline & (1) & $(2)$ \\
\hline Log of productivity $\mathrm{t}_{\mathrm{t}}$ & $\begin{array}{l}-0.182 \\
(0.042)\end{array}$ & \\
\hline Large entrants $\mathrm{t}_{\mathrm{t}-1}$ & $\begin{array}{c}0.026 \\
(0.042)\end{array}$ & $\begin{array}{l}-0.068 \\
(0.069)\end{array}$ \\
\hline $\mathrm{p} 10^{*}$ Large entrants $\mathrm{t}_{\mathrm{t}-1}$ & & $\begin{array}{c}0.136 \\
(0.122)\end{array}$ \\
\hline p10-p25*Large entrants $\mathrm{t}_{\mathrm{t}-1}$ & & $\begin{array}{c}0.104 \\
(0.121)\end{array}$ \\
\hline p25-p50*Large entrants $\mathrm{t}_{\mathrm{t}-1}$ & & $\begin{array}{l}-0.123 \\
(0.113)\end{array}$ \\
\hline p75-p90*Large entrants ${ }_{\mathrm{t}-1}$ & & $\begin{array}{l}-0.214 \\
(0.141)\end{array}$ \\
\hline p90*Large entrants $\mathrm{t}_{\mathrm{t}-1}$ & & $\begin{array}{l}-0.319 \\
(0.150)\end{array}$ \\
\hline Log of capital $\mathrm{t}_{\mathrm{t}}$ & $\begin{array}{l}-0.083 \\
(0.013)\end{array}$ & $\begin{array}{l}-0.079 \\
(0.013)\end{array}$ \\
\hline Log of population $t_{t}$ & $\begin{array}{c}0.033 \\
(0.025)\end{array}$ & $\begin{array}{c}0.078 \\
(0.023)\end{array}$ \\
\hline Log of population density $t_{t}$ & $\begin{array}{c}0.005 \\
(0.016)\end{array}$ & $\begin{array}{l}-0.012 \\
(0.015)\end{array}$ \\
\hline Year dummies & Yes & Yes \\
\hline No. of obs. & 7,376 & 7,376 \\
\hline \multicolumn{3}{|c|}{$\begin{array}{l}\text { NOTE: This table shows probit regressions on exit. Productivity } \\
\text { is estimated using } E D J_{l m} \text {. Reported standard errors (in paren- } \\
\text { theses) are robust to heteroscedasticity. Large entrants in pe- } \\
\text { riod t- } 1 \text { are defined as the five largest store types in the DELFI } \\
\text { data (hypermarkets, department stores, large supermarkets, large } \\
\text { grocery stores, and other stores). We use six percentile bins for } \\
\text { productivity in each local market and year, with p50-75 used as } \\
\text { reference group. }\end{array}$} \\
\hline
\end{tabular}

\section{Section F: Productivity decompositions}

We decompose aggregate productivity growth of all entrants, exits, and incumbents (due to data constraints we cannot measure the contribution of large entrants to aggregate productivity growth). We use three recent decompositions - the ones by Foster et al. (2001) (FHK) and Griliches and Regev (1995) (GR). ${ }^{7}$ Because we cannot determine the exact contribution of large entrants, our data allow us to decompose aggregate productivity growth due to entrants, exits, and incumbents. Industry-level productivity $\left(\Omega_{t}\right)$ can then be expressed as the weighted average productivity $\Omega_{t} \equiv$ $\sum_{j \in N} m s_{j t} \omega_{m t}$, where $N$ is the number of stores and $m s_{j t}=$ sales $_{j t} /$ sales $_{t}$.

${ }^{7}$ Olley and Pakes (1996), Melitz and Polanec (2012), Petrin and Levinsohn (2012), and Petrin and Sivadasan (2013) are other recent contributions. 
The change in retail food productivity from year $t$ to year $t^{\prime}$ can be written as

$$
\begin{aligned}
\Delta \Omega_{t, t^{\prime}}= & \sum_{j \in C_{t, t^{\prime}}} m s_{j t} \Delta \omega_{j t, t^{\prime}}+\sum_{j \in C_{t, t^{\prime}}} \Delta m s_{j t, t^{\prime}}\left(\omega_{j t}-\Omega_{t}\right) \\
& +\sum_{j \in C_{t, t^{\prime}}} \Delta m s_{j t, t^{\prime}} \Delta \omega_{j t, t^{\prime}}+\sum_{j \in E_{t, t^{\prime}}} m s_{j t^{\prime}}\left(\omega_{j t^{\prime}}-\Omega_{t}\right) \\
& -\sum_{j \in X_{m t, t^{\prime}}} m s_{j t}\left(\omega_{j t}-\Omega_{t}\right)
\end{aligned}
$$

where $\Delta$ is the difference operator $\left(\Delta \Omega_{t, t^{\prime}}=\Omega_{t^{\prime}}-\Omega_{t}\right) ; C_{t, t^{\prime}}$ is the set of continuing stores, i.e., operating in both $t$ and $t^{\prime} ; E_{t, t^{\prime}}$ is the set of entering stores, i.e., that operated in $t^{\prime}$ but not in $t$; and $X_{t, t^{\prime}}$ is the set of exiting stores, i.e., that operated in $t$ but not in $t^{\prime}$. This decomposition, derived by Foster et al. (2001)(FHK), is a modified version of the decomposition by Baily et al. (1992).

The decomposition (9) thus consists of five terms. The first term (Within) is the increase in productivity when the continuing stores increase their productivity at initial sales. The second term (Between) is the increase in productivity when continuing stores with above-average productivity expand their share of sales relative to stores with below-average productivity. The third term (Cross) captures the increase in productivity when continuing stores increase their market shares, while the fourth and fifth terms (Entry and Exit) are productivity increases due to entry and exit, respectively.

The second productivity decomposition used is given by Griliches and Regev (1995) (GR) and modified by FHK to allow for entry and exit:

$$
\begin{aligned}
\Delta \Omega_{t, t^{\prime}}= & \sum_{j \in C_{t, t^{\prime}}} \overline{m s}_{j} \Delta \omega_{j t, t^{\prime}}+\sum_{j \in C_{t, t^{\prime}}} \Delta m s_{j t, t^{\prime}}\left(\bar{\omega}_{j}-\bar{\Omega}\right) \\
& +\sum_{j \in E_{t, t^{\prime}}} m s_{j t^{\prime}}\left(\omega_{j t^{\prime}}-\bar{\Omega}\right) \\
& -\sum_{j \in X_{t, t^{\prime}}} m s_{j t}\left(\omega_{j t}-\bar{\Omega}\right)
\end{aligned}
$$

where a bar over a variable indicates the average of the variable across $t$ and $t^{\prime}$. The within term in the GR decomposition consists of the growth rates of continuing stores' productivity weighted by the average of their shares across $t$ and $t^{\prime}$. Both decompositions compare aggregate productivity of entering and existing stores, either to the aggregate productivity of 
all stores (FHK) or to the unweighted average of aggregate productivity of all stores (GR).

Results productivity decompositions. Aggregate productivity growth was about 9 percent from 1997 to 2002 (Table F.1). While overall industry growth is the same in all decompositions, the relative contributions of incumbents, entrants, and exits differ. In both GR and FHK, incumbent stores that increase their productivity at initial sales contribute about 8 percent and net entry 2-4 percent. Incumbent stores that increase productivity and market shares stand for 3.7 percent of the growth in FHK. The decomposition results confirm our findings based on large entrants, i.e., incumbents that increase their productivity and low productive stores that exit foster productivity growth in retail.

Table F.1: Decomposition of retail food productivity growth, 1997 to 2002

\begin{tabular}{|c|c|c|c|c|c|c|}
\hline \multirow[b]{2}{*}{$\begin{array}{l}\text { Overall } \\
\text { industry } \\
\text { growth }\end{array}$} & \multicolumn{6}{|c|}{ Percentage of growth from } \\
\hline & $\begin{array}{l}\text { Within } \\
\text { stores } \\
(1)\end{array}$ & $\begin{array}{l}\text { Between } \\
\text { stores } \\
(2)\end{array}$ & $\begin{array}{c}\text { Cross } \\
\text { stores } \\
(3)\end{array}$ & $\begin{array}{c}\text { Entry } \\
(4)\end{array}$ & $\begin{array}{l}\text { Exit } \\
(5)\end{array}$ & $\begin{array}{l}\text { Net entry } \\
(4)-(5)\end{array}$ \\
\hline \multicolumn{7}{|c|}{ A. Baily et al. (1992) / Foster et al. (2001) } \\
\hline 0.088 & 0.079 & -0.029 & 0.037 & 0.065 & 0.063 & 0.002 \\
\hline \multicolumn{7}{|c|}{ B. Griliches and Regev (1995) } \\
\hline 0.088 & 0.097 & -0.013 & & 0.043 & 0.038 & 0.004 \\
\hline
\end{tabular}




\section{References}

Ackerberg, D., L. Benkard, S. Berry, and A. Pakes (2007): "Econometric Tools for Analyzing Market Outcomes," Handbook of Econometrics, 6, 4171-4276.

Ai, C., and X. Chen (2003): "Efficient Estimation of Models with Conditional Moment Restrictions Containing Unknown Functions," Econometrica, 71(6), 1795-1843.

Baily, M., C. Hulten, and D. Campbell (1992): "Productivity Dynamics in Manufacturing Establishments," Brookings Papers on Economic Activity, pp. 187-249.

Bertrand, M., and F. Kramarz (2002): "Does Entry Regulation Hinder Job Creation? Evidence from the French retail industry," Quarterly Journal of Economics, 117(4), 1369-1413.

Doraszelski, U., And J. Jaumandreu (2013): "R\&D and Productivity: Estimating Endogenous Productivity," Review of Economic Studies, 80(4), 1338-1383.

Foster, L., J. Haltiwanger, and C. Krizan (2001): "The Link Between Aggregate and Micro Productivity Growth: Evidence from Retail Trade," NBER Working Paper 13783.

Griliches, Z., and H. Regev (1995): "Productivity and Firm Turnover in Israeli Industry: 1979-1988," Journal of Econometrics, 65, 175-203.

Hausman, J. (1997): The Economics of New Goodschap. Valuation of New Goods Under Perfect and Imperfect Competition, pp. 207-248. University of Chicago Press.

Hulten, C., and F. Wykoff (1981): chap. The Measurement of Economic Depreciation, in C. Hulten (ed.), Depreciation, Inflation, and Taxation of Income from Capital, Urban Institute Press, Washington, D.C. 
Maican, F., And M. Orth (2015): "A Dynamic Analysis of Entry Regulations and Productivity in Retail Trade," International Journal of Industrial Organization, 40, 67-80.

Melitz, M., And S. Polanec (2012): "Dynamic Olley-Pakes Productivity Decomposition with Entry and Exit," Mimeo, Princeton University.

Newey, W., ANd J. Powell (2003): "Instrumental Variables Estimation of Nonparametric Models," Econometrica, 71(3), 1557-1569.

Olley, S., And A. Pakes (1996): "The Dynamics of Productivity in the Telecommunications Equipment Industry," Econometrica, 64(6), 12631297.

Petrin, A., And J. Levinsohn (2012): "Measuring Aggregate Productivity Growth Using Plant-level Data," RAND Journal of Economics (forthcoming).

Petrin, A., and J. Sivadasan (2013): "Estimating Lost Output from Allocative Inefficiency, with Application to Chile and Firing Costs," Review of Economics and Statistics, 95(1), 286ii $\frac{1}{2} 301$.

Petrin, A., and K. Train (2010): "A Control Function Approach to Endogeneity in Consumer Choice Models," Journal of Marketing Research, XLVII, 3-13.

Schivardi, F., And E. Viviano (2011): "Entry Barriers in Retail Trade," Economic Journal, 121(155), 145-170.

Staiger, D., And J. Stock (1997): "Instrumental Variables Regression with Weak Instruments," Econometrica, 65(3), 557-586.

Swedish Competition Authority (2001:4): "Kan Kommunerna Pressa Matpriserna? (Can the Municipalities Put Pressure on Prices?)," Technical Report 4, Stockholm. (2004:2): "Konsumenterna, Matpriserna och Konkurrensen (Consumers, Retail Food Prices, and Competition)," Technical Report 2, Stockholm. 
Wooldridge, J. (2002): Econometric Analysis of Cross Section and Panel Data. MIT Press, Cambridge, MA. 